\title{
Rapidly restoring biological soil crusts and ecosystem functions in a severely disturbed desert ecosystem
}

\author{
Lindsay P. Chiquoine, ${ }^{1,3}$ Scott R. Abella, ${ }^{1}$ and Matthew A. Bowker ${ }^{2}$ \\ ${ }^{1}$ School of Life Sciences, University of Nevada, 4505 S. Maryland Parkway, Las Vegas, Nevada 89154-4004 USA \\ ${ }^{2}$ School of Forestry, Northern Arizona University, 200 East Pine Knoll Drive, Flagstaff, Arizona 86011-5018 USA
}

\begin{abstract}
Restoring biological soil crusts (biocrusts) in degraded drylands can contribute to recovery of ecosystem functions that have global implications, including erosion resistance and nutrient cycling. To examine techniques for restoring biocrusts, we conducted a replicated, factorial experiment on recently abandoned road surfaces by applying biocrust inoculation (salvaged and stored dry for two years), salvaged topsoil, an abiotic soil amendment (wood shavings), and planting of a dominant perennial shrub (Ambrosia dumosa). Eighteen months after treatments, we measured biocrust abundance and species composition, soil chlorophyll $a$ content and fertility, and soil resistance to erosion. Biocrust addition significantly accelerated biocrust recovery on disturbed soils, including increasing lichen and moss cover and cyanobacteria colonization. Compared to undisturbed controls, inoculated plots had similar lichen and moss composition, recovered $43 \%$ of total cyanobacteria density, had similar soil chlorophyll content, and exhibited recovery of soil fertility and soil stability. Inoculation was the only treatment that generated lichen and moss cover. Topsoil application resulted in partial recovery of the cyanobacteria community and soil properties. Compared to untreated disturbed plots, topsoil application without inoculum increased cyanobacteria density by $186 \%$ and moderately improved soil chlorophyll and ammonium content and soil stability. Topsoil application produced $22 \%$ and $51 \%$ of the cyanobacteria density $\mathrm{g}^{-1}$ soil compared to undisturbed and inoculated plots, respectively. Plots not treated with either topsoil or inoculum had significantly lower cyanobacteria density, soil chlorophyll and ammonium concentrations, and significantly higher soil nitrate concentration. Wood shavings and Ambrosia had no influence on biocrust lichen and moss species recovery but did affect cyanobacteria composition and soil fertility. Inoculation of severely disturbed soil with native biocrusts rapidly restored biocrust communities and soil stability such that restored areas were similar to undisturbed desert within three years. Using salvaged biocrust as inoculum can be an effective tool in ecological restoration because of its efficacy and simple implementation. Although salvaging biocrust material can be technically difficult and potentially costly, utilizing opportunities to salvage material in planned future disturbance can provide additional land management tools.
\end{abstract}

Key words: Biocrust; cyanobacteria; dryland; inoculation; Mojave Desert; restoration; soil fertility; soil stability.

\section{INTRODUCTION}

Diverse assemblages of lichens, bryophytes, fungi, and microorganisms, such as cyanobacteria, green algae, nematodes, and protozoa, are functionally important surface landscape features in many of the world's drylands (West 1990, Housman et al. 2007). Several studies highlight the significance of these soil assemblages (hereafter biocrusts) for soil surface stability (Belnap and Gillette 1998, Chaudhary et al. 2009), carbon cycling and sequestration (Elbert et al. 2012, Cantón et al. 2014), nitrogen cycling (Belnap 2002, Castillo-Monroy et al. 2010), surface hydrology (Warren 2003, Belnap 2006), ecosystem resilience (Kuske et al. 2012), and ecological

Manuscript received 28 May 2015; revised 21 September 2015; accepted 1 October 2015. Corresponding Editor: R. L. Sinsabaugh.

${ }^{3}$ E-mail: lindsay.chiquoine@unlv.edu restoration (Bowker 2007). Although they have low productivity, dryland systems significantly influence Earth's climate by comprising $41 \%$ of the terrestrial land area, $27 \%$ of global soil organic carbon, and $95 \%$ of soil inorganic carbon reserves (Safriel and Adeel 2005). Approximately $10-20 \%$ of the world's drylands are significantly degraded because of anthropogenic disturbances (Safriel and Adeel 2005). Reestablishing biocrust in disturbed drylands may assist with landscape restoration goals because of the significant ecological roles of biocrust organisms (Byers et al. 2006, Bowker 2007).

Loss of surface materials, such as biocrusts, reduce vital ecological functions in drylands and can result in undesirable or unpredictable ecosystem trajectories (Kuske et al. 2012, Concostrina-Zubiri et al. 2014). These trajectories can affect climate and air quality and are difficult to alter without restoring key natural functions of desert soils (Safriel and Adeel 2005). For 
example, anthropogenic perturbations that damage or remove biocrusts decrease carbon and nitrogen fixation, thereby increasing $\mathrm{CO}_{2}$ emissions and reducing soil nitrogen available to higher plants (Barger et al. 2006, Thomas and Dougill 2006), mobilize dust and alter surface soil and air temperatures (Pointing and Belnap 2012), and reduce air quality and impact human health (Safriel and Adeel 2005, Field et al. 2009, Metcalf et al. 2012).

After severe disturbance, desert soils require long periods to recover naturally. Cyanobacteria are typically the first to colonize soil surfaces after disturbance, and if conditions are suitable, lichens and mosses colonize to provide additional photosynthetic cover and soil stabilization (Belnap and Eldridge 2003, Lalley and Viles 2008, Belnap 2006). However, recovery of these organisms may require time frames longer than land management objectives require. Several factors affect natural recovery of biocrusts, including changes in abiotic landscape features because of disturbance (Neff et al. 2005), such as removal of surface substrates, the size of a disturbance, natural disturbance regimes (e.g., wind events), climate conditions, and changes in vegetation and biocrust propagule availability (Belnap 1993, Belnap and Eldridge 2003).

Restoring biocrusts to surfaces of disturbed soils may accelerate ecosystem recovery in degraded drylands, but it is unclear if reintroducing native biocrusts will result in a biocrust community and ecosystem functions similar to undisturbed communities. The few available laboratory and field studies (e.g., Maestre et al. 2006, Wang et al. 2009) suggest that amelioration of a disturbance, sufficient biocrust propagule availability, and supplementing resources (e.g., water and nutrients) can enhance biocrust and soil recovery. To examine a biocrust restoration technique, we tested the resilience of biocrust organisms to the stresses of salvage, storage, and field application, and the ability of reintroduced organisms to contribute to recovery of ecosystem functions. Specifically, we evaluated the effects of salvaged biocrust inoculation on biocrust composition, soil aggregate stability, and soil nitrogen pools. We also tested the reapplication of salvaged topsoil containing native biocrust species, the application of wood shavings mixed in with surface soils, and shade and protection to surface soils provided by the native shrub Ambrosia dumosa (A. Gray) Payne. We anticipated that (1) salvaged and stored biocrusts would survive, although show symptoms of stress; (2) inoculation with biocrusts and habitat treatments (e.g., planting shrubs) would accelerate biocrust recovery, soil fertility, and stability compared to untreated disturbance, although biocrust cover and functions would not reach levels found on undisturbed areas; and (3) topsoil reapplication alone would increase cyanobacteria, soil stability, and soil nitrogen, but would not enhance lichen or moss cover because of negative effects of the topsoil salvage and stockpiling process on these biocrust components.

\section{Methods}

\section{Study sites and experimental design}

The experiment was conducted along Northshore Road in Lake Mead National Recreation Area (LMNRA), $96 \mathrm{~km}$ northeast of Las Vegas, Nevada, in the Mojave Desert, USA (36 $18^{\prime} 42.870^{\prime \prime}$ N 114 $29^{\prime} 18.819^{\prime \prime}$ W). Elevation among study sites ranged between 400 and $500 \mathrm{~m}$. Surface soils consisted of loamy, hyperthermic, shallow Typic Petrogypsids or Leptic Haplogypsids (Lato 2006) with significant biocrust cover compared to soil with low gypsum content (Appendix S1: Fig. S2). Vegetation physiognomy is typical of eastern Mojave Desert gypsiferous soil with a sparse cover of shrubs and perennial grasses (Appendix S1). Annual precipitation is $140 \mathrm{~mm}$ and occurs mostly in winter with the remainder falling as summer monsoon rains in some years (Western Regional Climate Center 2010). Summer high temperatures commonly exceed $37^{\circ} \mathrm{C}$ and are often paired with less than $25 \%$ relative humidity. Winter months are mild with afternoon temperatures around $15^{\circ} \mathrm{C}$ (Gorelow and Skrbac 2005).

We applied biocrust treatments to recently disturbed road side segments along the new and old road corridor. In fall 2008, surface material and plants along road segments were salvaged for use in study treatments after construction was complete. Surface material from roadside segments (topsoil; 5-12 cm depth) was scalped with large machinery and stockpiled uncovered near its source location in piles 1-3 m high. Biocrust cover was observed on surface material before topsoil scalping. Fourteen months after construction began topsoil material was reapplied using heavy equipment $(5-30 \mathrm{~cm}$ depth) to construction areas alongside the newly realigned road after surface contouring (Appendix S1: Fig. S3). No topsoil was applied where the old road bed was removed for realignment. In areas where no topsoil was reapplied, subsurface soil sourced on site was used for contouring. Individuals of the native shrub A. dumosa were salvaged and cared for at a nursery following procedures in Abella et al. (2015). Salvaged plants were transported from the nursery to field locations 15 months after initial construction disturbance began and planted in topsoil and non-topsoil construction segments. Additionally, before construction began, biocrust material was salvaged $(2-5 \mathrm{~cm}$ soil depth) with shovels and stored dry and with minimal light at a local storage facility in long, flat, plastic containers to minimize damage from burial. Storage facility temperatures were monitored and did not exceed $30^{\circ} \mathrm{C}$. Biocrust treatments were applied in September 2010, 10 months after topsoil application and shrub plantings were completed, and two years after the road realignment project began.

Treatments were implemented as a four-factor, mixedeffects experimental design containing two levels (presence or absence) of each factor applied to plot units $1 \times 1 \mathrm{~m}$ in size, except for topsoil, which was applied to 
entire road side segments. Treatment factors included: topsoil (randomly selected segments along the road which significantly ranged in size), perennial planting (A. dumosa individuals with canopies $20-40 \mathrm{~cm}$ in diameter; randomly selected within segments), wood shavings applied at a plot level (kiln dried Pinus spp./Abies concolor; Rosebud Horse Bedding, Grangeville, Idaho, USA) and incorporated into surface soils ( $2 \mathrm{~cm}$ depth; $20 \%$ area evenly distributed), and biocrust inoculation (discrete fragments $0.5-3 \mathrm{~cm}$ thick and $0.5-5 \mathrm{~cm}$ in diameter) applied to the soil surface at a plot level $(30 \%$ area; evenly distributed). Each of these 16 treatment combinations was replicated five times, totaling 80 plots $1 \times 1 \mathrm{~m}$ in size across 13 non-continuous and randomly selected, disturbed construction segments. Plots receiving a planted shrub were situated with the plant at the center.

During plot establishment on the disturbed areas, biocrusts were not observed on surface material and appeared to be absent. At the time treatments were established, each plot received $1 \mathrm{~L}$ of water sprayed across the surface, and the top $2 \mathrm{~cm}$ of surface soil was roughened using a hand trowel. Wood shavings were then incorporated into surface soils on assigned plots, and biocrust inoculum was applied last. All plots were caged with $1.25-\mathrm{cm}$ diameter galvanized wire with the bottom edges buried, creating an $80 \mathrm{~cm}$ high fence to deter herbivory and trampling. One liter of water was applied over 2-3 min with a backpack sprayer twice a month during winter months (November-February) and once a month during spring months (March-May) to extend biocrust hydration time by $1-2 \mathrm{~d}$. If a watering day was scheduled on a day that received natural precipitation, the watering event was rescheduled for the following day.

Additionally, six undisturbed reference plots $1 \times 1 \mathrm{~m}$ in size were established randomly within a $200-\mathrm{m}$ zone around the original road bed and within the same stratified soil units as experimental plots. Locations were randomly generated using ArcGIS 9.1 (ERSI, Redlands, California, USA).

\section{Species composition}

In April 2012, 18 months after treatments were completed, experimental and undisturbed reference plots were assessed. We measured lichen and moss cover (visually estimated across whole plots). Species were identified to the finest taxonomic resolution possible, and unknown species were identified in the laboratory. The two Collema Wigg. species, gelatinous soil lichens, were difficult to distinguish in the field and were recorded at the generic level.

To characterize cyanobacteria communities, four cores ( $3 \mathrm{~cm}$ diameter) at $1 \mathrm{~cm}$ depth were obtained from standardized locations in each plot $(25 \mathrm{~cm}$ from the center of the plot in the cardinal directions or just inside the drip line of the planted shrub, if present). In the laboratory, 1-3 mm of dried surface material was scraped off using a razor blade sanitized after each plot. Subsamples were compiled per plot and pulverized. Using $0.01 \mathrm{~mL}$ of a 1:100 serial dilution, subsamples were observed using light microscopy under $400 \times$ magnification and cyanobacteria were counted. Organisms were identified to the finest resolution possible to family, genus, or species and grouped by morphology. Identification was difficult with light microscopy for some species due to similarities between species, and not all differentiating characteristics are distinguishable with this technique (Boyer et al. 2002, Alwathnani and Johansen 2011). To assist with species identification, a 1:10 dilution per plot was used to inoculate $10 \mathrm{~g}$ of autoclaved native gypsiferous soil in $10 \mathrm{~cm}$ diameter Petri dishes. Dishes were placed in a Percival model GL-36VL Intellus Environmental Controller (Percival Scientific, Perry, Iowa, USA). This chamber was set to a light irradiance of $100 \mu \mathrm{mol} \cdot \mathrm{m}^{-2} \cdot \mathrm{s}^{-1}$ and a diurnal setting with dark/light temperatures of $15^{\circ} \mathrm{C} / 25^{\circ} \mathrm{C}$ for 3-5 weeks. Potential for contamination was examined by including 10 non-inoculated plates, and no contamination was detected. Dishes were examined under a stereo microscope to identify possible missed species during the serial dilution. Species were isolated and verified using light microscopy under $400 \times$ magnification.

\section{Functional characteristics}

Chlorophyll fluorescence, soil chlorophyll $a$ and available nitrogen $\left(\mathrm{NH}_{4}-\mathrm{N}\right.$ and $\left.\mathrm{NO}_{3}-\mathrm{N}\right)$, and soil aggregate stability were used as quantitative indicators for recovery of biocrusts and soils. From undisturbed and inoculated plots, four Collema specimens $(3-5 \mathrm{~mm}$ diameter) were acquired from standard areas within each plot (approximately $30 \mathrm{~cm}$ from the center of the plot in the cardinal directions, or just inside the drip line of planted shrubs, if present) to measure chlorophyll fluorescence as an index for biocrust health and recovery (Maxwell and Johnson 2000). In the laboratory, samples were dark-adapted for $12 \mathrm{~h}$ in a dry state in a growth chamber set at $25^{\circ} \mathrm{C}$ prior to hydration. Specimens were hydrated with distilled water while in a dark-adapted state. Dark- and light-adapted fluorescence was measured using a FMS 2 pulse-modulated fluorometer (Hansatech Instruments, Norfolk, England) at room temperature after $6 \mathrm{~h}$ of hydration. Fluorescence measures were repeated at 12,24 , and $48 \mathrm{~h}$ of hydration with samples dark-adapted between measurements. The quantum yield of photosystem II photochemistry was calculated (Maxwell and Johnson 2000) and used for analysis. To characterize soil chlorophyll and available nitrogen concentrations, four cores ( $3 \mathrm{~cm}$ diameter) at $1 \mathrm{~cm}$ depth were obtained per test from standardized locations (adjacent to cyanobacteria samples) in each plot. For soil chlorophyll analysis, 1-3 $\mathrm{mm}$ of surface material was scraped off each core using a razor blade sanitized after each plot, composited per plot, and pulverized. Soil samples were frozen until analysis and analyzed with spectrophotometry (Beckman DU-64, Beckman Instruments, Fullerton, California, USA) immediately 
following methanol extraction (Castle et al. 2011). Available nitrogen samples were compiled per plot and pulverized. A 2-M $\mathrm{KCl}$ solution was used to extract available nitrogen within $6-8 \mathrm{~h}$ of collection, and samples were frozen until analysis and analyzed with flow injection colorimetry for $\mathrm{NH}_{4}-\mathrm{N}$ and $\mathrm{NO}_{3}-\mathrm{N}$ (modified from Esque et al. 2010). Soil stability was tested in all plots following Herrick et al. (2001) using six peds collected from standardized locations in each plot.

\section{Data analysis}

To elucidate responses to treatments, each dependent variable was analyzed in a split-split plot analysis of variance (ANOVA). Cover of moss species was low in all plots and was analyzed as total moss cover. Additionally, lichen species were analyzed on a generic level separately to identify treatment effects on particular lichen genera. Topsoil, biocrust inoculation, wood shavings, and perennial planting and all two-way, three-way, and four-way interactions among them were designated as fixed effects. Topsoil was applied to entire road segments and was therefore tested over the random effect of road segment within topsoil treatment. The other three treatments, biocrust inoculation, wood shavings, and perennial planting, were applied factorially in an incomplete block design within road segments. Significance of these terms and their interactions was tested over their respective interactions with road segment within topsoil treatment. Transformations were applied to variables to meet assumptions of ANOVA and to reduce influences of outliers (Appendix S2). However, not all variables met assumptions despite transformation. We therefore computed $P$ values and standard errors for means in two ways (Appendix S2: Table S1). For the normal model, $P$ values for the model and post-hoc tests were assessed in SAS 9.2 (Proc Mixed; SAS Institute, Cary, North Carolina, USA). As appropriate, back-transformed means and standard error are reported. For the permutation-based model, $P$ values for the model and post-hoc tests were computed from 999 permutations using distlm software (Anderson 2001, McArdle and Anderson 2001), and standard errors estimated from 1000 bootstrap samples in SAS 9.2. The variable or each member of the set of variables for each analysis was scaled to its range. The resulting values were converted to a distance matrix using the Bray-Curtis dissimilarity equation (Legendre and Legendre 1998). For significant terms in the models, Bonferroni post-hoc tests were conducted.

A priori pairwise comparisons were conducted between all treatment plots and undisturbed plots following the same model design above. Undisturbed plots did not contain our study manipulations. These plots served as an additional control along with disturbed, untreated plots. They were included in the overall model (and thus allowed to contribute to total variance), but they were excluded from consideration in the main effects and their interactions in the model.
Fluorescence was sampled differently from the other response variables: sampling was limited to plots treated with biocrust inoculum and included four time points within each sampling location (plot). We therefore used a split-split plot (repeated measure) ANOVA model in SAS 9.2. The model included the fixed effects of topsoil (tested over road segment within topsoil), wood shavings and perennial planting (tested over their interactions with road segment within topsoil), time (tested over error variance), and their two-way and three-way interactions with each other.

Additionally, to elucidate relationships among response variables, Spearman's rank correlations were computed. To analyze the similarity of species composition of biocrust communities, Sørensen indices were calculated between treatments and with undisturbed reference plots.

\section{Results}

\section{Lichens and mosses}

Disturbance removed lichen and moss cover, and 18 months after experimental treatment plots were established, there was no visual evidence aboveground of lichen or moss recovery in any plot that did not receive biocrust inoculation (Fig. 1). The other three treatments (topsoil, wood shavings, and perennial planting) did not have any main effects on biocrust cover or interactions with inoculation (Table 1). Biocrust cover in inoculated treatment plots did not significantly differ from cover in the undisturbed reference plots (Appendix S2).

The similarity of lichen and moss species composition between inoculated and undisturbed reference plots ranged from 58\% to 91\% (Appendix S2). Most of the species compositional difference was driven by moss species presence. Mosses were detected in only $48 \%$ of the inoculated plots and did not significantly contribute to total cover when present $(0.02-4.5 \%$ cover of mosses). The most common species included Syntrichia caninervis Mitten, Aloina bifrons (De Not.) Delg., and Bryum sp. Hedw. In both inoculated and undisturbed reference plots, most of the biocrust cover consisted of the soil lichen Collema (12-45\%), followed by the soil lichens Placidium $(0.03-10 \%)$ and Peltula $(0.03-75 \%)$. Other treatments did not affect individual species soil lichen cover (Appendix S2). Additional species also occurred with less frequency across and within inoculated plots and contributed less to biocrust cover. A list of species detected is in Appendix S2.

\section{Cyanobacteria}

There was a significant interaction between topsoil and inoculation treatments for cyanobacteria density. Other treatments did not affect total cyanobacteria density (Appendix S2). Experimental plots with no topsoil or inoculation treatments contained minimal cyanobacteria 

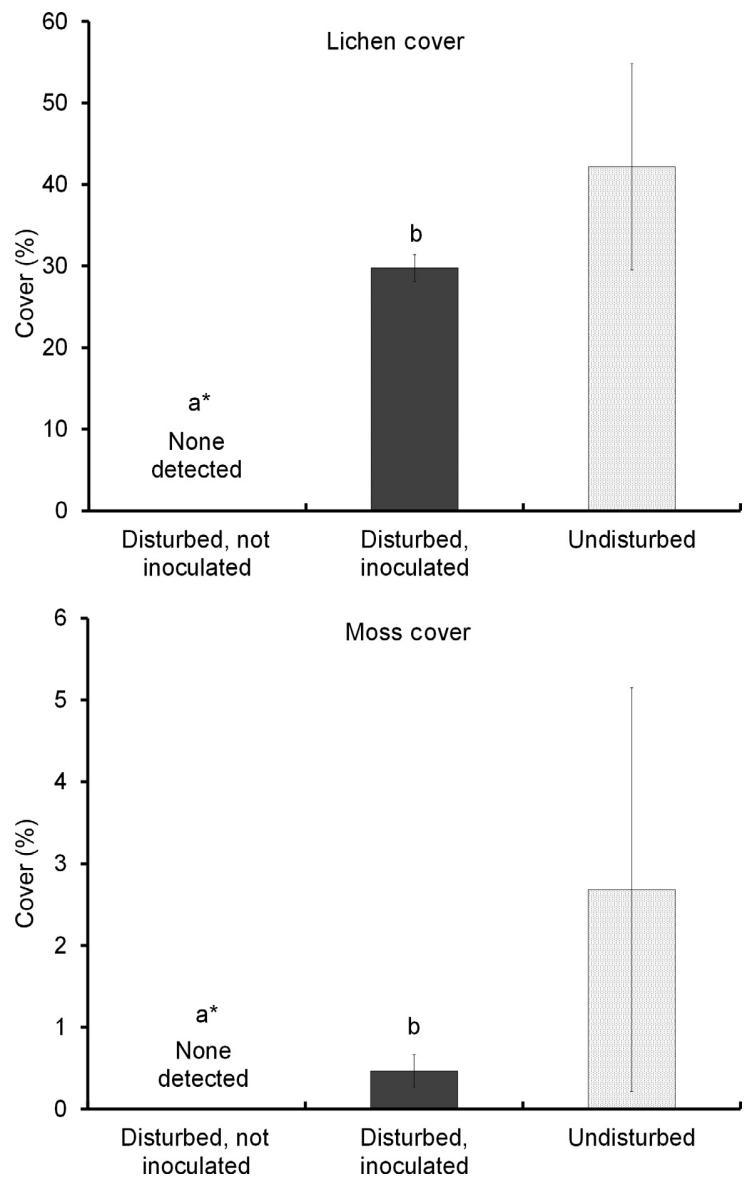

FIG. 1. Response of average biocrust cover 18 months after biocrust restoration treatments were established in a restoration experiment in the Mojave Desert, USA. Biocrust inoculation was the only treatment that resulted in lichen and moss presence and cover. Lichens and mosses were not detected in non-inoculated plots. Other treatments (topsoil reapplication, wood shavings, and planting a perennial plant) had no effect on cover and had no interactions with inoculation treatment. Error bars indicate $\pm 1 \mathrm{SE}$. Letters denote statistical significance between treatments $(P<0.05)$ and exclude undisturbed reference plots. Asterisks denote treatments that significantly differ $(P<0.05)$ from undisturbed plots.

density. Without a topsoil or inoculation treatment, cyanobacteria recovery was significantly reduced compared to plots with either or both of these treatments (Fig. 2). Plots receiving topsoil contained significantly greater $(186 \%)$ cyanobacteria density compared to experimental plots without topsoil or inoculation treatments, although this was a modest increase relative to the minimal levels found in disturbed, unrestored soils. In contrast, biocrust inoculation significantly increased cyanobacteria. Orders of magnitude greater cyanobacteria density were detected in inoculated plots compared to non-inoculated plots. The addition of topsoil with biocrust inoculation provided an additional $20 \%$ increase in density, although this was an increase from an already large value.
Biocrust-inoculated plots contained a cyanobacteria density similar to reference plots (Appendix S2). Most detected species were filamentous, and significant effects on filamentous cyanobacteria from treatments followed the same trends as for total cyanobacteria. However, for non-filamentous cyanobacteria, there were additional interactions detailed in Appendix S2. In general, treatments additional to biocrust inoculation increased nonfilamentous cyanobacteria and in some cases resulted in significantly greater non-filamentous cyanobacteria than undisturbed reference plots. Without biocrust inoculum present, increases in cyanobacteria were small and not statistically significant with additional treatments.

Cyanobacteria species composition varied between treatments and undisturbed reference plots (Appendix $\mathrm{S} 2$ ). Biocrust-inoculated plots tended to be most similar to undisturbed plots $(65-69 \%$ similar in species composition), while plots which did not include inoculation were the least similar to undisturbed plots (17-35\% similar). When topsoil was present, treatment plots were more similar to biocrust-inoculated plots (33-72\%) and undisturbed plots $(33-68 \%)$ than they were to plots that excluded inoculation and topsoil treatments $(0 \%)$. Without inoculation or topsoil, wood shavings and perennial plant plots were least similar to undisturbed plots (0-19\%). Wood shavings and perennial plants increased similarity to undisturbed plots when added with biocrust, and they reduced similarity to undisturbed plots when added with topsoil. Plots that contained either a perennial plant or wood shavings, or both, ranged from $22 \%$ to $50 \%$ similar to untreated disturbed soils. Most of this variation occurred with the species composition of non-filamentous cyanobacteria species.

\section{Chlorophyll fluorescence}

Fluorescence quantum yield of Collema samples showed no significant responses to topsoil, wood shavings, or perennial planting treatments (Appendix S2). Fluorescence did vary over time and decreased with hydration longer than $12 \mathrm{~h}$ (Appendix S2: Fig. S3). Fluorescence measured from treatment plot samples also did not significantly differ from undisturbed plot samples. However, fluorescence in treatment plots was qualitatively higher than in undisturbed plots.

\section{Soil chlorophyll a}

Topsoil and inoculation both increased soil chlorophyll, while wood shavings and perennial planting had no main effects or interactions with topsoil or inoculation (Appendix S2). In disturbed plots that did not receive topsoil or inoculation, soil chlorophyll was minimal (Fig. 3), indicating low photosynthetic biomass present in the soil. Topsoil addition moderately increased chlorophyll content in soils, while biocrust inoculation significantly increased soil chlorophyll. Inoculation increased soil chlorophyll to levels similar to undisturbed plots. 
TABLE 1. Summary of the effects of biological soil crust inoculation (BSC), topsoil reapplication (TS), wood shavings (WS), and planting of a perennial plant (PP) on biological soil crust cover and soil properties, Mojave Desert, USA.

\begin{tabular}{|c|c|c|c|c|c|c|}
\hline Treatments & BSC cover & $\begin{array}{c}\text { Cyanobacteria } \\
\text { density }\end{array}$ & $\begin{array}{c}\text { Chlorophyll } \\
a\end{array}$ & $\mathrm{NH}_{4}-\mathrm{N}$ & $\mathrm{NO}_{3}-\mathrm{N}$ & Soil stability \\
\hline Biological soil crust (BSC) & + & + & + & + & & + \\
\hline Topsoil reapplication (TS) & & + & $+*$ & & - & + \\
\hline Wood shavings (WS) & & & & - & & \\
\hline Perennial plant (PP) & & & & & - & \\
\hline $\mathrm{BSC} \times \mathrm{TS}$ & & + & & & & \\
\hline \multicolumn{7}{|l|}{$\mathrm{BSC} \times \mathrm{WS}$} \\
\hline \multicolumn{7}{|l|}{$\mathrm{BSC} \times \mathrm{PP}$} \\
\hline \multicolumn{7}{|l|}{$\mathrm{TS} \times \mathrm{WS}$} \\
\hline $\mathrm{TS} \times \mathrm{PP}$ & & & & + & - & \\
\hline $\mathrm{WS} \times \mathrm{PP}$ & & & & & $+/-$ & \\
\hline $\mathrm{BSC} \times \mathrm{TS} \times \mathrm{WS}$ & & & & & $+/-*$ & \\
\hline $\mathrm{BSC} \times \mathrm{TS} \times \mathrm{PP}$ & & & & $+1-*$ & & \\
\hline \multicolumn{7}{|l|}{$\mathrm{BSC} \times \mathrm{WS} \times \mathrm{PP}$} \\
\hline \multicolumn{7}{|l|}{$\mathrm{TS} \times \mathrm{WS} \times \mathrm{PP}$} \\
\hline \multicolumn{7}{|l|}{$\mathrm{BSC} \times \mathrm{TS} \times \mathrm{WS} \times \mathrm{PP}$} \\
\hline Disturbance, no treatment & - & - & - & - & + & - \\
\hline
\end{tabular}

Notes: Response variables are cover of biological soil crust (BSC; includes lichen and moss cover), cyanobacteria density $\left(\mathrm{g}^{-1}\right.$ soil), soil chlorophyll $a$, soil available nitrogen (two forms, $\mathrm{NH}_{4}-\mathrm{N}$ and $\mathrm{NO}_{3}-\mathrm{N}$ ), and soil stability (following the rank scale from Herrick et al. 2001). Positive or negative sign indicates direction of significant effect $(P<0.05)$. Asterisks indicate moderate effect $(P<0.10)$. Positive and negative signs together indicate interactions when the effects of interactions were not additive. Statistical results including $F$ statistics and $P$ values are available in Appendix $\mathrm{S} 2$.

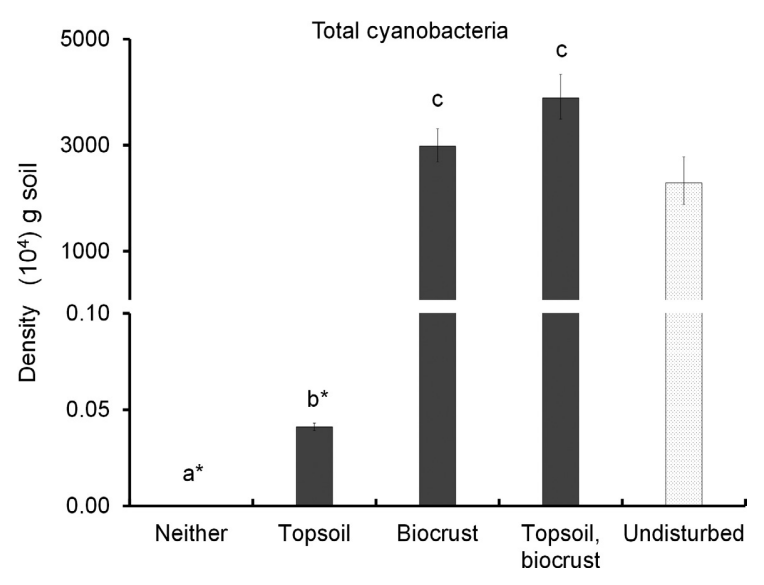

FIG. 2. Response of cyanobacteria density 18 months after biocrust restoration treatments were established in a restoration experiment in the Mojave Desert, USA. Topsoil and biocrust inoculation had a two-way interaction. Other restoration treatments (wood shavings and perennial planting) did not affect total cyanobacteria. Disturbed plots not receiving either treatment are labelled as neither. Error bars indicate $\pm 1 \mathrm{SE}$. Letters denote statistical significance $(P<0.05)$ between treatments and exclude undisturbed reference plots. Asterisks denote treatments that significantly differ $(P<0.05)$ from undisturbed plots.

\section{Soil nitrogen}

Surface soil nitrogen concentrations had mixed responses to disturbance and treatments depending on the form of nitrogen (Appendix S2). Disturbance significantly decreased $\mathrm{NH}_{4}-\mathrm{N}$ compared to undisturbed plots.
Within treatment plots, there were several responses of $\mathrm{NH}_{4}-\mathrm{N}$ to treatments (Fig. 4). In disturbed treatment plots with biocrust inoculation, $\mathrm{NH}_{4}-\mathrm{N}$ was significantly increased to levels similar to undisturbed plots. Plots with inoculation and a perennial plant tended to have the highest mean concentration of $\mathrm{NH}_{4}-\mathrm{N}$. The addition of wood shavings by themselves significantly decreased $\mathrm{NH}_{4}-\mathrm{N}$, and it also decreased $\mathrm{NH}_{4}-\mathrm{N}$ when combined with other treatments. Within the perennial planting treatment, there was a qualitative trend for $\mathrm{NH}_{4}-\mathrm{N}$. With topsoil or perennial planting treatments, $\mathrm{NH}_{4}-\mathrm{N}$ increased. However, when both or neither topsoil nor perennial planting treatments were present, $\mathrm{NH}_{4}-\mathrm{N}$ decreased.

Compared to $\mathrm{NH}_{4}-\mathrm{N}$, disturbance had the opposite effect on soil $\mathrm{NO}_{3}-\mathrm{N}$ by significantly increasing $\mathrm{NO}_{3}-\mathrm{N}$ relative to undisturbed plots. For $\mathrm{NO}_{3}-\mathrm{N}$, there were two significant two-way interactions between treatment effects (Appendix S2). Topsoil and perennial planting both influenced $\mathrm{NO}_{3}-\mathrm{N}$ (Fig. 4). Levels of $\mathrm{NO}_{3}-\mathrm{N}$ were significantly higher when neither perennial planting nor topsoil was present in treatment plots. If one or both of these treatments were present, $\mathrm{NO}_{3}-\mathrm{N}$ was significantly decreased and decreased to levels more similar to undisturbed plots. Plots without topsoil tended to have the highest $\mathrm{NO}_{3}-\mathrm{N}$ concentration, except when wood shavings were also present with other treatments. Wood shavings without perennial planting significantly increased $\mathrm{NO}_{3}-\mathrm{N}$, while perennial planting qualitatively reduced $\mathrm{NO}_{3}-\mathrm{N}$ when present with wood shavings. 

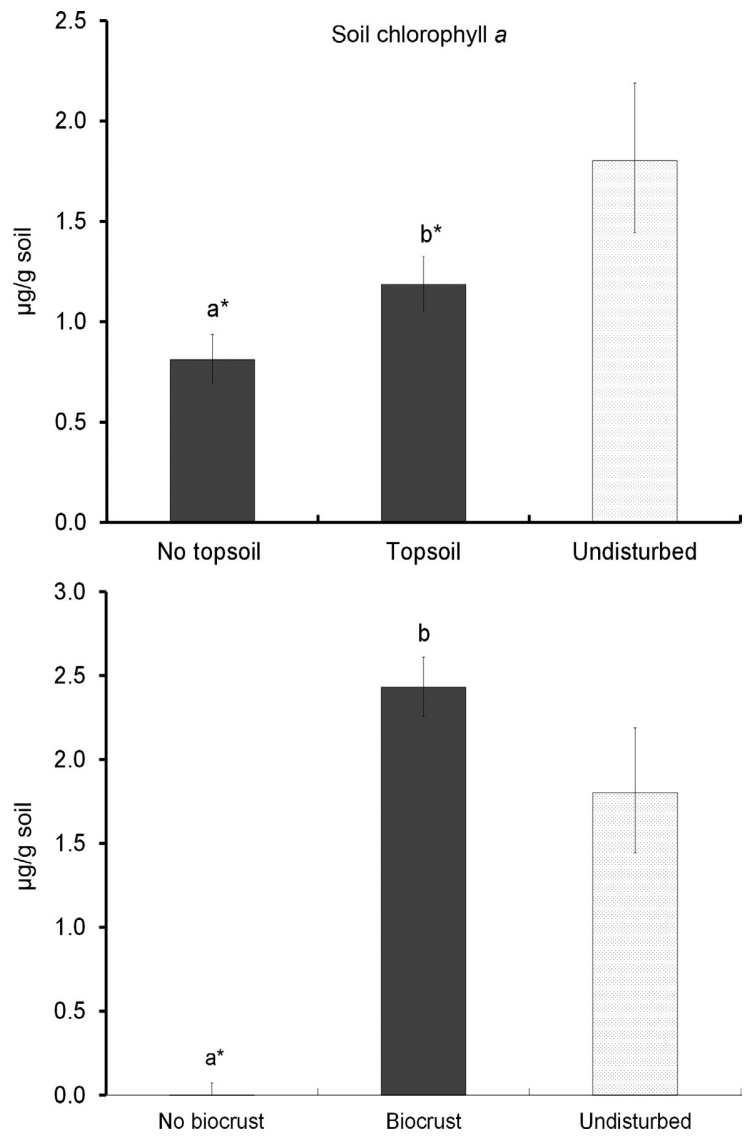

FIG. 3. The significant effects of topsoil reapplication (top panel) and biocrust inoculation (bottom panel) on soil chlorophyll $a$ content in experimental treatment plots in a restoration experiment in the Mojave Desert, USA. Plots were assessed 18 months after biocrust restoration treatments were established. The additional treatments of wood shavings and perennial planting did not have significant effects on soil chlorophyll. Error bars indicate $\pm 1 \mathrm{SE}$. Letters denote statistical significance between treatments $(P<0.05)$ and exclude undisturbed reference plots. Asterisks denote treatments that significantly differ $(P<0.05)$ from undisturbed plots.

\section{Soil stability}

Disturbance significantly reduced surface soil stability compared to undisturbed plots (Appendix S2). In treatment plots, topsoil addition and inoculation independently increased soil stability significantly (Fig. 5). However, inoculation alone increased soil stability comparable to undisturbed plots. Additional treatments had no effects or interactions with topsoil or inoculation on soil stability.

\section{Relationships among treatments}

Biocrust cover, particularly lichen cover, had a moderate to strong positive correlation with cyanobacteria density, soil chlorophyll, $\mathrm{NH}_{4}-\mathrm{N}$, and soil stability (Appendix S2). These response variables increased to levels similar to undisturbed plots when biocrust inoculation was present in disturbed treatment plots. Nitrate was not correlated with other response variables, although plots with higher $\mathrm{NO}_{3}-\mathrm{N}$ were also more likely to not have biocrust inoculation or topsoil and to have significantly lower cyanobacteria density and species diversity.

\section{DisCusSION}

\section{Response to treatments}

A main goal of this study was to test whether salvaged biocrust can be used as an inoculant to enhance biocrust reestablishment and functioning after severe disturbance. We found that biocrust inoculation significantly enhanced recovery of biocrust communities and surface soil fertility and stability on severely disturbed soil surfaces. Other inoculation studies have also demonstrated increased biocrust functioning (Belnap 1993, Buttars et al. 1998, Maestre et al. 2006). For example, several studies have demonstrated that greater biocrust cover results in higher carbon and nitrogen fixation (Belnap 2006, Chamizo et al. 2012).

We also found that biocrust material survived or recovered after salvage, two years of dry storage, and field application, and reestablished under field conditions with limited additional treatments. Our source material was obtained from within the same soil units as our study sites and contained species acclimated to the soil and climate conditions. Inoculation with locally salvaged biocrust hastened reestablishment of both macro and microorganisms, and increased the ecological functions contributed by biocrust organisms to levels similar to those in undisturbed biocrust communities in less than two years.

While inoculation with salvaged material assisted rapid recovery of biocrust communities, there was significant variation in the cyanobacteria communities with the other treatments. Non-inoculated plots did have some cyanobacteria colonization, but total cyanobacteria density and species richness were significantly lower compared to inoculated plots. Furthermore, in some plots which also did not receive topsoil, no cyanobacteria were detected using our methods 18 months after treatment plots were established and three years after disturbance. Topsoil and exposed subsurface soils that were used for contouring were exposed to environmental conditions for an additional 10 months, which included a winter and spring biocrust growing season. These plots had significant physical crusts but low soil stability. Cyanobacteria were significantly improved when topsoil was present, which improved surface soil stability, but the cyanobacteria density was still much lower than undisturbed plots. Several factors were likely contributing to these surfaces remaining resistant to cyanobacterial colonization, including poor surface soil conditions and low propagule availability. 

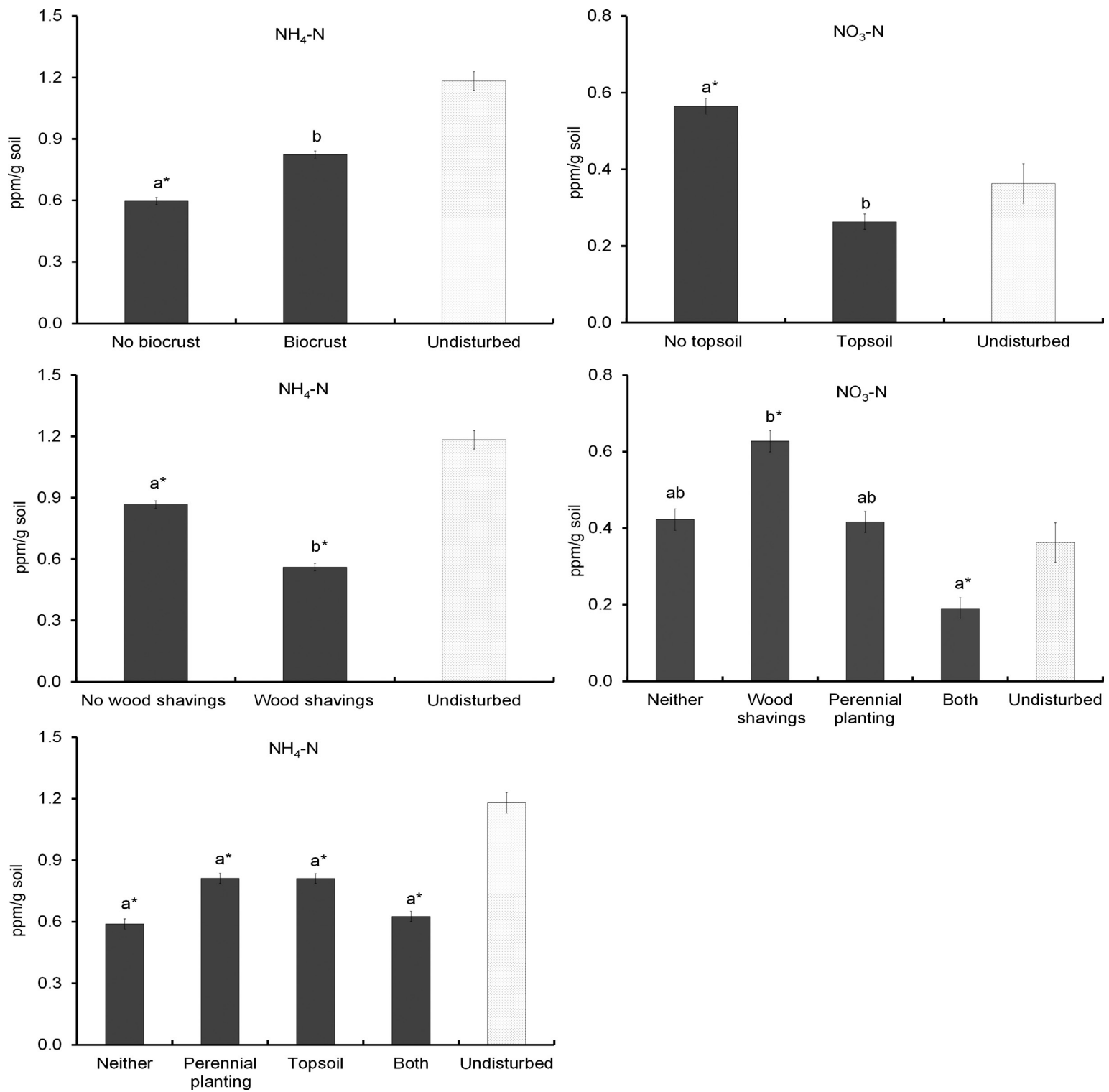

FIG. 4. Significant effects by and interactions between biocrust inoculation, topsoil reapplication, wood shavings, and perennial planting treatments on soil ammonium (left) and nitrate (right) in disturbed experimental treatment plots in a restoration experiment in the Mojave Desert, USA. Plots were assessed 18 months after biocrust restoration treatments were established. Disturbed plots not receiving either treatment are labelled as neither. Error bars indicate \pm 1 SE. Letters denote significance $(P<0.05)$ among experimental treatments. Asterisks denote treatment difference $(P<0.05)$ with undisturbed reference plots.

In these same plots with low cyanobacteria detection, we observed significantly lower chlorophyll concentrations (a proxy for photosynthetic biomass), lower $\mathrm{NH}_{4}-\mathrm{N}$ concentrations, higher $\mathrm{NO}_{3}-\mathrm{N}$ concentrations, and poor soil stability compared to inoculated treatment plots and undisturbed plots. The low chlorophyll concentrations indicate a lack of photosynthetic biomass in these soils and support the result of low cyanobacteria detection. It is unclear if shifts in dominant nitrogen forms on the soil surface are of biological origin (stemming from soil bacteria, biocrust, or previously established vegetation), or a result of exposure of subsurface soil $\mathrm{NO}_{3}-\mathrm{N}$ (Jackson et al. 2004) through the road realignment activities. Physical crust development could also have impeded organism establishment. Physical crusts are resistant to erosion and increase water runoff and restrict water permeability (Mokdad et al. 2007). These surfaces may also restrict cyanobacteria from colonializing the soil surface because of physical crusting and run off activity. Additionally, the road reconstruction area consisted of large patches of land with severe surface disturbance that lacked significant biocrust surface material.

Cyanobacteria species composition was most similar between inoculated treatment plots and undisturbed plots, 

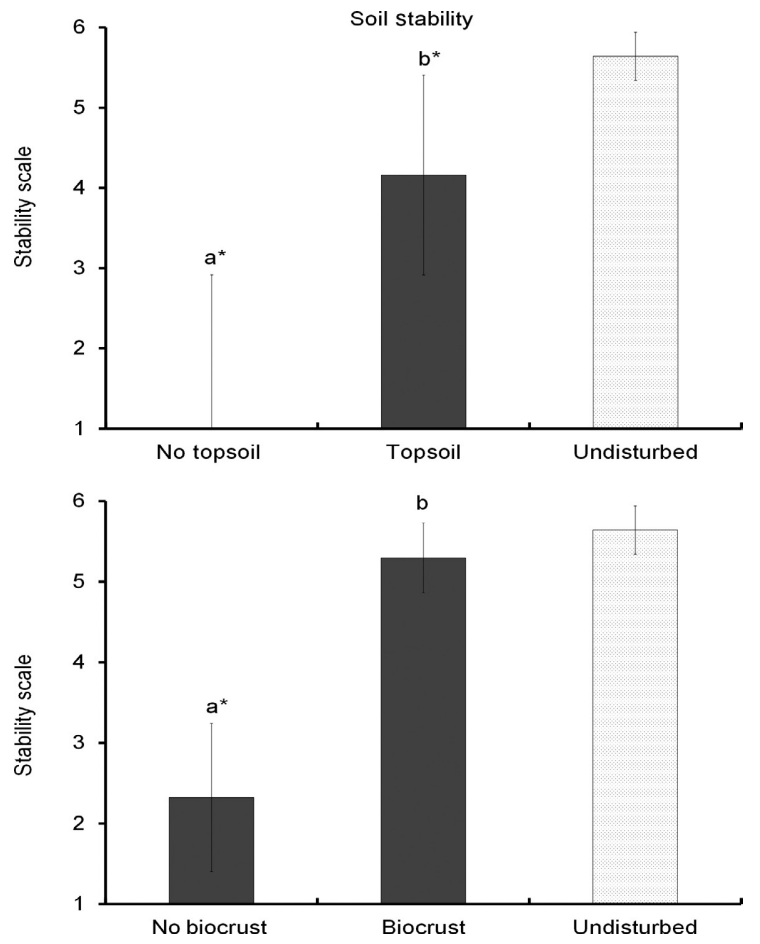

FIG. 5. Significant effects of topsoil reapplication (top panel) and biocrust inoculation (bottom panel) on soil stability in disturbed experimental treatment plots in a restoration experiment in the Mojave Desert, USA. The additional treatments of wood shavings and perennial planting did not have significant effects on soil stability. Plots were assessed 18 months after biocrust restoration treatments were established using the soil stability measure of Herrick et al. (2001). Error bars indicate \pm 1 SE. Letters denote significance $(P<0.05)$ among experimental treatments. Asterisks denote treatment difference $(P<0.05)$ with undisturbed reference plots.

although additional treatments appeared to influence variation in non-filamentous cyanobacteria species composition and density. In inoculated treatment plots and undisturbed plots, the cyanobacteria community was dominated by filamentous cyanobacteria, which are important for initial soil stabilization (Hu et al. 2002). The magnitude of the increase or reduction in total cyanobacteria density by other treatments when biocrust was present was small compared to biocrust inoculation alone. However, when applied with biocrusts, other treatments had statistical and biological significance on nonfilamentous cyanobacteria. It is unclear how the different cyanobacteria organisms interact with each other, symbiotically or competitively, in this soil environment, or how species diversity could affect reestablishing biocrust communities.

Variation in species composition can result from changes in the soil environment, the order in which species are reintroduced after disturbances, and different rates of organism recolonization, growth, and regeneration (Digham et al. 2005, Garcia-Pichel et al. 2013). Several studies have demonstrated that soil properties, such as particle-size distributions, the chemical environment and surface microtopography, affect biocrust community composition (Chamizo et al. 2012, Williams et al. 2012), and that disturbances to surface soils can negatively affect microbial movement and depth of microbial colonization (Belnap et al. 2003). Although we did not measure other soil physical properties, several studies have demonstrated that topsoil salvage, storage, and reapplication can alter soil particle-size distribution, soil pore size, and other properties that affect water permeability and retention (Potter et al. 1988, Wick et al. 2009). Topsoil salvage and stockpiling also damages soil crust components through burial (Rao et al. 2012), reducing photosynthetic biomass and organisms that contribute to the soil nitrogen cycle (Barger et al. 2006). Additionally, physical surface crusts also formed in all disturbed areas and likely restricted movement of soil microorganisms even with biocrust inoculation. Wood shavings and biocrust treatments increased surface soil heterogeneity, which slows surface water movement and increases water permeability and residency ( $\mathrm{Li}$ et al. 2012). This benefits biocrust organisms that require hydration events to be biologically active (Lange et al. 1998, Belnap 2002, Rajeev et al. 2013). We placed biocrust material on top of roughened soil surfaces, and the properties of the disturbed soils were likely consistent with the non-inoculated surfaces and limited deeper water permeability and microbial movement.

It is uncertain if the variation in non-filamentous cyanobacteria stemming from wood shavings and perennial planting treatments was because of changes in the surface environment or a direct effect on the soil organisms. Surface materials, such as wood shavings, and perennial plants affect dust capture, and dust can be a carrier of airborne cyanobacteria (Field et al. 2009, Metcalf et al. 2012, Pointing and Belnap 2012). Wood shavings may also have affected surface hydrology because of increased surface heterogeneity and soil organic content. Vegetation contributes to stability and provides shade for extended hydration of surface material after a precipitation event (Pointing and Belnap 2012). Fertile islands also develop around desert perennials, creating nutrient-enriched soils (Bolling and Walker 2002), and in the near-term the shrubs shaded the soil surface. Collective changes in the soil environment from the combination of treatments likely contributed to the shift in species composition by benefiting those species or microbial morphologies most responsive to the changes in soil conditions.

\section{Importance of biocrust restoration}

Natural recovery of biocrust systems is often beyond usual land management time frames. Biocrust degradation results in environmental conditions (e.g., loss of carbon and nitrogen fixation; soil erosion) that can exacerbate the legacy of disturbance and create environmental problems (e.g., increased airborne dust; Field et al. 2009, Pointing and Belnap 2012). Biocrust species 
are inherently slow colonizers because of biotic and abiotic factors that limit growth and productivity, and succession occurs slowly and is limited by disturbance regimes (Belnap and Eldridge 2003, Pointing and Belnap 2012). Additionally, attributes of drylands (e.g., low productivity and precipitation and extreme temperature regimes) contribute to slow recovery. Cyanobacteria are the first species to colonize new surfaces and have been observed to reestablish within 10-20 yr after disturbance was removed (Anderson et al. 1982, Belnap 1993, Belnap and Warren 2002). Under appropriate conditions, if a surface stabilizes and propagules are available, lichens and mosses colonize within several decades to centuries (Belnap and Warren 2002, Belnap and Eldridge 2003, Read et al. 2011). Some studies have observed natural recovery of mosses (e.g., Xu et al. 2008, Xiao et al. 2014) and lichens (e.g., Belnap and Warren 2002, Lalley and Viles 2008) within years to decades. However, more time is required for recovery if disturbances remove propagules. Additionally, changes in species assemblages alter ecosystem functions of biocrust and can influence how a recovering system will respond to naturally occurring perturbations (Elmqvist et al. 2003, Digham et al. 2005, Housman et al. 2006), resulting in unpredictable trajectories (Kuske et al. 2012, Concostrina-Zubiri et al. 2014).

Actively restoring biocrust components has the potential to mitigate landscape degradation or reverse long-term ecological damage. Traditionally, restoration efforts have focused on reestablishing a historical trajectory after a disturbance, partly relying on the process of succession to guide biotic recovery. This uses an assumption that once biotic environmental factors are reestablished, natural succession will return to guide recovery of biotic contributors and their functions (Suding et al. 2004, Bowker 2007). However, attributes of some biotic community members, such as biocrust species, can alter the efficacy of this method of restoration. Common restoration strategies fail because ecosystem components and their interactions are more complex than anticipated (Geist and Galatowitsch 1999, Byers et al. 2006). Reintroducing biocrust species to a disturbed environment reduces the time for recolonization and begins the process of establishment of biocrusts and their functions.

Additionally, biocrust restoration can have longlasting benefits with global implications (e.g., Yang et al. 2014), including enhanced recovery of ecosystem functions like soil stability. Desert systems cover a significant proportion of terrestrial systems, and biocrusts significantly contribute to the cover of surface environments in these systems and provide long-term carbon sequestration (Lal 2004, Elbert et al. 2012, Li et al. 2012, Maestre et al. 2013) and protection against erosion ( $\mathrm{Hu}$ et al. 2002, Warren 2003, Belnap 2006). Protection against erosion reduces dust, ameliorating atmospheric changes from human-induced land degradation and benefitting human health (Field et al. 2009, Metcalf et al. 2012, Pointing and Belnap 2012).

\section{Strategies and implications of biocrust restoration}

Biocrust restoration has two main approaches: salvaging biocrust from a source site and using the material as inoculum in degraded areas (e.g., Belnap 1993 and as we did) or culturing organisms in laboratories for field application (e.g., Hu et al. 2002). Both strategies have benefits and limitations. Salvaging surface materials close to a treatment area has several advantages. Selecting biocrusts that are adapted to local soil environments and climate conditions avoids the additional challenges of testing organisms for adaptability. Many biocrust species are slow to recolonize and recover after disturbance and reintroducing organisms can reduce the overall time required for establishment. Also, salvaged material may contain species that are difficult to cultivate in a laboratory or prepare for field application (Stark et al. 2014).

However, salvage operations can be technically challenging and cost prohibitive. Specific challenges associated with salvage operations are uncertain. Source material can be difficult to locate. Large projects require greater amounts of biocrust material to use as inoculum. If material is not used immediately after salvage, proper storage (e.g., low humidity and temperature-controlled facility) of material and preparation (e.g., hardening) for field application is necessary. Mosses and lichens can survive long periods in storage, although survival times and conditions necessary for maximum survival may differ between species and phenotypes (Alpert 2000, Lüttge et al. 2011).

For field application, biocrust inoculants are under similar environmental conditions as naturally recovering organisms. Inoculants may respond to changes in the soil environment and have difficulty reestablishing if soil properties are significantly altered because of disturbance. Although salvage has several disadvantages, utilizing opportunities to salvage material in sites under development or planned for future disturbance could be advantageous for land managers. Additionally, estimating minimum inoculation levels and providing supplementary resources (e.g., water, nutrients; Maestre et al. 2006) could increase the extent to which the salvaged material can be used.

Several studies suggest the efficacy of cultivation of biocrust species as a restoration tool (Bu et al. 2013). Some biocrust species are easily and rapidly cultivated, such as mosses and cyanobacteria. For example, Xiao et al. (2011) demonstrated that moss-dominated crusts can be artificially cultivated in a laboratory and used to improve soil surface hydrology. Wang et al. (2009) found that cultivated cyanobacteria could immobilize sand dunes. Cultivation provides an alternative to locating large quantities of source material. Additionally, species can be selected for cultivation and applied to field sites strategically for guiding biocrust communities to support restoration goals, such as soil stabilization or carbon sequestration. 
Cultivation also has limitations. The approach requires appropriate facilities, equipment, resources, and time to manufacture large quantities of material under controlled environmental conditions. Also, not all species are easily cultivated under laboratory conditions, such as some lichen species. Some species that are easily cultivated may not necessarily survive under field conditions without additional time and resources for hardening or because of differences in soil or environmental conditions (Doherty 2014, Stark et al. 2014). The source material is also important for artificial cultivation because within-species variation may occur across environmental gradients (Doherty 2014). Choosing species with higher phenotypic plasticity may alleviate this issue. While artificial cultivation requires additional study for implementation in different dryland environments, it has already been shown to be an effective strategy for reintroducing some biocrust species like mosses and cyanobacteria in degraded habitats.

Both salvage and cultivation techniques require further research, particularly for application in hot deserts that have additional obstacles to biocrust recovery (e.g., short growing season, temperature extremes, and limited precipitation). If both techniques are used in conjunction, barriers to biocrust restoration may be reduced. For example, cultivated cyanobacteria can be used for initial soil stabilization and conditioning (e.g., Wang et al. 2009), while natively sourced salvage material can be used to inoculate with species more difficult to cultivate in a laboratory or to increase species and functional diversity. Additional research is necessary to test resource augmentation techniques with biocrust inoculation in field settings. Several studies, with and without goals of testing restoration techniques, have reported effects of nutrients and nutrient additions (e.g., Maestre et al. 2006, Delgado-Baquerizo et al. 2013), which can guide future research.

\section{Conclusion}

Biocrusts in drylands influence ecosystem functions on landscape scales that have global implications owing to the enormous portion of Earth's terrestrial system dominated by drylands. Disturbance to surface material reduces vital ecosystem contributions by surface organisms that also affect soil productivity, habitat quality, and biodiversity. Mitigation actions, such as salvaging and replacing topsoil and using organic material to reduce soil erosion, are often used in land management activities. However, we demonstrated that these activities alone are not as effective as biocrust inoculation for accelerating surface soil recovery. Assisted biocrust recovery can contribute to mitigation of legacy effects of land degradation and may potentially reverse damage while accelerating restoration of soil stability and nutrient cycling. Our approach took advantage of a unique opportunity to utilize salvaged biocrusts, which included native lichens, mosses, cyanobacteria, and other soil organisms. To our knowledge no one has tested the efficacy of using salvaged and stored biocrusts for field treatments. We observed accelerated recovery of biocrust composition in less than two years with minimal additional treatments. Our results suggest that inoculants retained species composition through several stress events.

Salvaging biocrusts can be an effective tool in ecological restoration because of its efficacy and simple implementation. Collection of biocrusts can be performed as part of planned restoration of known future disturbances, although this may be technically challenging and costly depending on the extent of material collection. Biocrust salvaging could be used in conjunction with biocrust cultivation to provide land managers with multiple options for planned restoration. Additional research is necessary to identify the best practices for removing and storing biocrusts and maximizing their effectiveness for restoration applications.

\section{ACKNOWLEDGMenTs}

Funding was provided by Lake Mead National Recreation Area and implemented through a cooperative agreement between the National Park Service (NPS) and the University of Nevada, Las Vegas (UNLV). We thank Alice Newton (NPS) and Sharon Altman (UNLV) for facilitating and administrating this study; Joslyn Curtis, Pamela Sinanian, Cayenne Engel, and Alex Suazo (UNLV) for field and laboratory assistance; Llo Stark and Joshua Greenwood for use of and assistance with laboratory equipment; Stanley Smith and Lloyd Stark (UNLV) for suggestions on study design; and two anonymous reviewers for helpful comments on the manuscript.

\section{Literature Cited}

Abella, S. R., L. P. Chiquoine, A. C. Newton, and C. H. Vanier. 2015. Restoring a desert ecosystem using soil salvage, revegetation, and irrigation. Journal of Arid Environments 115:44-52.

Alpert, P. 2000. The discovery, scope and puzzle of desiccation tolerance in plants. Plant Ecology 151:5-17.

Alwathnani, H., and J. R. Johansen. 2011. Cyanobacteria in soils from a Mojave Desert ecosystem. Monographs of the Western North American Naturalist 5:71-89.

Anderson, M. J. 2001. A new method for non-parametric multivariate analysis of variance. Austral Ecology 26:32-46.

Anderson, D. C., K. T. Harper, and S. R. Rushforth. 1982. Recovery of cryptogamic soil crusts from grazing on Utah winter ranges. Journal of Range Management 35:355-359.

Barger, N. N., J. E. Herrick, H. van Zee, and J. Belnap. 2006. Impacts of biological soil crust disturbance and composition of $\mathrm{C}$ and $\mathrm{N}$ loss from water erosion. Biogeochemistry 77:247-263.

Belnap, J. 1993. Recovery rates of cryptobiotic crusts: inoculation use and assessment methods. Great Basin Naturalist 53:89-95.

Belnap, J. 2002. Nitrogen fixation in biological soil crusts from southeast Utah, USA. Biology and Fertility of Soils 35:128-135.

Belnap, J. 2006. The potential roles of biological soil crust in dryland hydrologic cycles. Hydrological Processes 20:3159-3178. 
Belnap, J., and D. Eldridge. 2003. Disturbance and recovery of biological soil crust. Pages 363-383 in J. Belnap, and O. L. Lange, editors. Biological soil crusts: structure, function and management. Springer-Verlag, Berlin, Germany.

Belnap, J., and D. A. Gillette. 1998. Vulnerability of desert biological soil crust to wind erosion: the influences of crust development, soil texture, and disturbance. Journal of Arid Environments 39:133-142.

Belnap, J., and S. D. Warren. 2002. Patton's tracks in the Mojave Desert, USA: an ecological legacy. Arid Land Research and Management 16:245-258.

Belnap, J., S. Phillips, M. Duniway, and R. Reynolds. 2003. Soil fertility in deserts: a review on the influence of biological soil crusts and the effects of soil surface disturbance on nutrient inputs and losses. Pages 245-252 in A. S. Alsharhan, W. W. Wood, A. S. Goudie, A. Fowler, and E. M. Abdellatif, editors. Desertification in the third millennium. Swets \& Zeitlinger Publishers, Lisse, The Netherlands.

Bolling, J. D., and L. R. Walker. 2002. Fertile island development around perennial shrubs across a Mojave Desert chronosequence. Western North American Naturalist 62:88-100.

Bowker, M. A. 2007. Biological soil crust rehabilitation in theory and practice: an unexploited opportunity. Restoration Ecology 15:13-23.

Boyer, S. L., J. R. Johansen, V. R. Flechtner, and G. L. Howard. 2002. Phylogeny and genetic variance in terrestrial microcoleus (Cyanophyceae) species based on sequence analysis of the $16 \mathrm{~S}$ rRna gene and associated 16S-23S ITS region1. Journal of Phycology 38:1222-1235.

Bu, C., S. Wu, Y. Xie, and X. Zhang. 2013. The study of biological soil crusts: hotspots and prospects. CLEAN-Soil, Air, Water 41:899-906.

Buttars, S. M., L. L. St. Clair, J. R. Johansen, J. C. Sray, M. C. Payne, B. L. Webb, R. E. Terry, B. K. Pendleton, and S. D. Warren. 1998. Pelletized cyanobacterial soil amendments: laboratory testing for survival, escapability, and nitrogen fixation. Arid Land Research and Management 12:165-178.

Byers, J. E., K. Cuddington, C. G. Jones, T. S. Talley, A. Hastings, J. G. Lambrinos, J. A. Crooks, and W. G. Wilson. 2006. Using ecosystem engineers to restore ecological systems. Trends in Ecology and Evolution 21:493-500.

Cantón, Y., J. R. Román, S. Chamizo, and M. J. Moro. 2014. Dynamics of organic carbon losses by water erosion after biocrust removal. Journal of Hydrology and Hydromechanics 62:258-268.

Castillo-Monroy, A. P., F. T. Maestre, M. Delgado-Baquerizo, and A. Gallardo. 2010. Biological soil crusts modulate nitrogen availability in semi-arid ecosystems: insights from a Mediterranean grassland. Plant and Soil 333:21-34.

Castle, S. C., C. D. Morrison, and N. N. Barger. 2011. Extraction of chlorophyll $a$ from biological soil crusts: a comparison of solvents for spectrophotometric determination. Soil Biology and Biochemistry 43:853-856.

Chamizo, S., Y. Cantón, I. Miralles, and F. Domingo. 2012. Biological soil crust development affects physicochemical characteristics of soil surface in semiarid ecosystems. Soil Biology and Biochemistry 49:96-105.

Chaudhary, V. B., M. A. Bowker, T. E. O'Dell, J. B. Grace, A. E. Redman, M. C. Rilling, and N. C. Johnson. 2009. Untangling the biological contributions to soil stability in semiarid shrublands. Ecological Applications 19:110-122.

Concostrina-Zubiri, L., E. Huber-Sannwald, I. Martínez, J. F. Flores, J. A. Reyes-Agüero, A. Escudero, and J. Belnap. 2014. Biological soil crusts across disturbance-recovery scenarios: effect of grazing regime on community dynamics. Ecological Applications 24:1863-1877.
Delgado-Baquerizo, M., L. Morillas, F. T. Maestre, and A. Gallardo. 2013. Biocrusts control the nitrogen dynamics and microbial functional diversity of semi-arid soils in response to nutrient additions. Plant and Soil 372:643-654.

Digham, R. K., C. H. Watts, and D. A. Norton. 2005. Are systems with strong underlying abiotic regime more likely to exhibit alternative stable states? Nordic Society Oikos 110:409-416.

Doherty, K. D. 2014. Moss farming: how cultivation of biocrust bryophytes may be the key to arid soil restoration. Thesis. Northern Arizona University, Flagstaff, Arizona, USA.

Elbert, W., B. Weber, S. Burrows, J. Steinkamp, B. Büdel, M. O. Andreae, and U. Pöschl. 2012. Contribution of cryptogamic covers to the global cycles of carbon and nitrogen. Nature GeoScience 5:459-462.

Elmqvist, T., C. Folke, M. Nyström, G. Peterson, J. Bengtsson, B. Walker, and J. Norberg. 2003. Response diversity, ecosystem change, and resilience. Frontiers in Ecology and the Environment 1:488-494.

Esque, T. C., J. P. Kaye, S. E. Eckert, L. A. DeFalco, and C. R. Tracy. 2010. Short-term soil inorganic N pulse after experimental fire alters invasive and native annual plant production in a Mojave Desert shrubland. Oecologia 164:253-263.

Field, J. P., J. Belnap, D. D. Breshears, J. C. Neff, G. S. Okin, J. J. Whicker, T. H. Painter, S. Ravi, M. C. Reheis, and R. L. Reynolds. 2009. The ecology of dust. Frontiers in Ecology and the Environment 8:423-430.

Garcia-Pichel, F., V. Loza, Y. Marusenko, P. Mateo, and R. M. Potrafka. 2013. Temperature drives the continentalscale distribution of key microbes in topsoil communities. Science 340:1574-1577.

Geist, G., and S. M. Galatowitsch. 1999. Reciprocal model for meeting ecological and human needs in restoration projects. Conservation Biology 13:970-979.

Gorelow, A. S., and P. H. Skrbac. 2005. Climate of Las Vegas, Nevada. Department of Commerce, National Oceanic and Atmospheric Administration, National Weather Service.

Herrick, J. E., W. G. Whitford, A. G. de Soyza, J. W. Van Zee, K. M. Havstad, C. A. Seybold, and M. Walton. 2001. Field soil aggregate stability kit for soil quality and rangeland health evaluations. Catena 44:27-35.

Housman, D. C., H. H. Powers, A. D. Collins, and J. Belnap. 2006. Carbon and nitrogen fixation differ between successional stages of biological soil crusts in Colorado Plateau and Chihuahuan Desert. Journal of Arid Environments 66:620-634.

Housman, D. C., C. M. Yeager, B. J. Darby, R. L. Sanford, C. R. Kuske, D. A. Neher, and J. Belnap. 2007. Heterogeneity of soil nutrients and subsurface biota in a dryland ecosystem. Soil Biology and Biochemistry 39:2138-2149.

$\mathrm{Hu}, \mathrm{C}$, Y. Yiu, L. Song, and D. Zhang. 2002. Effects of desert soil algae on the stabilization of fine sands. Journal of Applied Phycology 14:281-292.

Jackson, R. B., S. T. Berthrong, C. W. Cook, E. G. Jobbágy, and R. L. McCulley. 2004. Comment on "A reservoir of nitrate beneath desert soils." Science 304:51.

Kuske, C. R., C. M. Yeager, S. Johnson, L. O. Ticknor, and J. Belnap. 2012. Response and resilience of soil biocrust bacterial communities to chronic physical disturbance in arid shrublands. International Society for Microbial Ecology Journal 6:886-897.

Lal, R. 2004. Carbon sequestration in dryland ecosystems. Environmental Management 33:528-544.

Lalley, J., and H. A. Viles. 2008. Recovery of lichen-dominated soil crusts in a hyper-arid desert. Biodiversity and Conservation 17:1-20. 
Lange, O. L., J. Belnap, and H. Reichenberger. 1998 Photosynthesis of the cyanobacterial soil-crust lichen Collema tenax from arid lands in southern Utah, USA: role of water content on light and temperature responses of $\mathrm{CO}_{2}$ exchange. Functional Ecology 12:195-202.

Lato, L. J. 2006. Soil survey of Clark County area, Nevada. U.S. Department of Agriculture, Natural Resources Conservation Service, U.S. Government Printing Office, Washington, D.C., USA.

Legendre, P., and L. Legendre. 1998. Numerical ecology. Elsevier, Amsterdam, The Netherlands.

Li, X. R., P. Zhang, Y. G. Su, and R. L. Jia. 2012. Carbon fixation by biological soil crusts following revegetation of sand dunes in arid desert regions of China: a four-year field study. Catena 97:119-126.

Lüttge, U., E. Beck, and D. Bartels, editors. 2011. Plant desiccation tolerance. Springer, Berlin, Germany.

Maestre, F. T., N. Martín, B. Díaz, R. López, F. Santos, I. Luque, and J. Cortina. 2006. Watering, fertilization, and slurry inoculation promote recovery of biological soil crust function in degraded soils. Microbial Ecology 52:365-377.

Maestre, F. T., C. Escolar, M. Ladrón de Guevara, J. L. Quero, R. Lázaro, M. Delgado-Baquerizo, V. Ochoa, M. Berdugo, B. Gozalo, and A. Gallardo. 2013. Changes in biocrust cover drive carbon cycle responses to climate change in drylands. Global Change Biology 19:3835-3847.

Maxwell, K., and G. N. Johnson. 2000. Chlorophyll fluorescence: a practical guide. Journal of Experimental Botany 51:659-668.

McArdle, B. H., and M. J. Anderson. 2001. Fitting multivariate models to community data: a comment on distance based redundancy analysis. Ecology 82:290-297.

Metcalf, J. S., R. Richard, P. A. Cox, and G. A. Codd. 2012. Cyanotoxins in desert environments may present rick to human health. Science of the Total Environment 421:118-123.

Mokdad, G., O. Alshihabi, and L. Stroosnijder. 2007. Microstructure of gypsiferous crust and its importance to unsaturated soil behavior. Springer Proceedings in Physics 112:33-40.

Neff, J. C., R. L. Reynolds, J. Belnap, and R. Lamothe. 2005. Multi-decadal impacts of grazing on soil physical and biogeochemical properties in southeast Utah. Ecological Applications 15:87-95.

Pointing, S. B., and J. Belnap. 2012. Microbial colonization and controls in dryland systems. Nature Reviews Microbiology 10:51-562.

Potter, K. N., F. S. Carter, and E. C. Doll. 1988. Physical properties of constructed and undisturbed soils. Soil Science Society of America Journal 52:1435-1438.

Rajeev, L., U. N. da Rocha, N. Klitgord, E. G. Luning, J. Fortney, S. D. Axen, P. M. Shih, and A. Mukhopadhyay. 2013. Dynamic cyanobacterial response to hydration and dehydration in a desert biological soil crust. International Society for Microbial Ecology Journal 7:2178-2191.

Rao, B., Y. Liu, S. Lan, P. Wu, W. Wang, and D. Li. 2012. Effects of sand burial stress on the early developments of cyanobacterial crusts in the field. European Journal of Soil Biology 48:48-55.
Read, C. F., D. H. Duncan, P. A. Vesk, and J. Elith. 2011. Surprisingly fast recovery of biological soil crusts following livestock removal in southern Australia. Journal of Vegetation Science 22:905-916.

Safriel, U., and A. Adeel. 2005. Dryland systems. Pages 623-662 in R. M. Sassan, R. J. Scholes, and A. Neville, editors. Ecosystem and human well-being: current state and trends. Vol. 1. Island Press, Washington, D.C.

Stark, L. R., J. L. Greenwood, J. C. Brinda, and M. J. Oliver. 2014. Physiological history may mask the inherent inducible desiccation tolerance strategy of the desert moss Crossidium crassinerve. Plant Biology 16:935-946.

Suding, K. N., K. L. Gross, and G. R. Houseman. 2004. Alternative states and positive feedbacks in restoration ecology. Trends in Ecology and Evolution 19: 46-53.

Thomas, A. D., and A. J. Dougill. 2006. Distribution and characteristics of cyanobacterial soil crusts in the Molopo Basin, South Africa. Journal of Arid Environments 64:270-283.

Wang, W., Y. Liu, D. Li, C. Hu, and B. Rao. 2009. Feasibility of cyanobacterial inoculation for biological soil crusts formation in desert area. Soil Biology and Biochemistry 41:926-929.

Warren, S. D. 2003. Synopsis: influence of biological soil crusts on arid land hydrology and soil stability. Biological soil crusts: structure, function and management. Pages 349-360 in J. Belnap, and O. L. Lange, editors. Ecological studies, 150. Springer-Verlag, Berlin, Germany.

West, N. E. 1990. Structure and function of microphytic soil crusts in wildland ecosystems of arid and semi-arid regions. Advances in Ecological Research 20:179-223.

Western Regional Climate Center. 2010. http://www.wrcc.dri. edu/. Accessed 20 March 2011. Reno, Nevada, USA.

Wick, A. F., P. D. Stahl, L. J. Ingram, and L. Vicklund. 2009. Soil aggregation and organic carbon in short-term stockpiles. Soil Use and Management 25:311-319.

Williams, A. J., B. J. Buck, and M. A. Beyene. 2012. Biological soil crusts in the Mojave Desert, USA: micromorphology and pedogenesis. Soil Science Society of America Journal 76:1685-1695.

Xiao, B., Q. H. Wang, Y. G. Zhao, and M. A. Shao. 2011. Artificial culture of biological soil crust and its effects on overland flow and infiltration under simulated rainfall. Applied Soil Ecology 48:11-17.

Xiao, B., Y. Zhao, H. Wang, and J. Wu. 2014. Natural recovery of moss-dominated biological soil crusts after surface soil removal and their long-term effects on soil water conditions in a semi-arid environment. Catena 120:1-11.

Xu, S., C. Yin, M. He, and Y. Wang. 2008. A technology for rapid reconstruction of moss-dominated soil crusts. Environmental Engineering Science 25:1129-1138.

Yang, H., X. Li, Z. Wang, R. Jia, L. Liu, Y. Chen, Y. Wei, Y. Goa, and G. Li. 2014. Carbon sequestration capacity of shifting sand dune after establishing new vegetation in the Tengger Desert, northern China. Science of the Total Environment 478:1-11.

\section{SUPPORTING INFORMATION}

Additional supporting information may be found in the online version of this article at http://onlinelibrary.wiley.com/ doi/10.1890/15-0973.1/suppinfo 
Chiquoine, Lindsay P., Scott R. Abella, and Matthew A. Bowker

Rapidly restoring biological soil crusts and ecosystem functions in a severely disturbed desert ecosystem

APPENDIX S1. Supplementary study site information, including vegetation composition descriptions and photographs of gypsum soil communities in the eastern Mojave Desert, USA.

\section{Dominant vegetation}

The dominant vegetation in gypsiferous soil communities in Lake Mead National Recreation Area, located in the eastern Mojave Desert, USA, consists of Ambrosia dumosa (A. Gray) Payne, Atriplex spp. L., Ephedra torreyana S. Watson, Psorothamnus fremontii (Torr. ex A. Gray) Barneby, and occasional patches of Pleuraphis rigida Thurb. Larrea tridentata (DC.) Coville is also common, but varies in its contribution of percent cover to the community. Surface cover consists mostly of biological soil crusts (10-80 \% cover; Fig. S1.1) and vegetation cover is low (4-10 \%; Fig. S1, Fig. S2). The vegetation community structure and species composition on alluvial soils within the region differ from gypsiferous soil communities. Perennial vegetation on alluvial soils is dominated by L. tridentata and A. dumosa (Fig. S2; Abella et al. 2012). Vegetation cover on alluvial soil tends to also be low, ranging from $10-30 \%$ cover. 


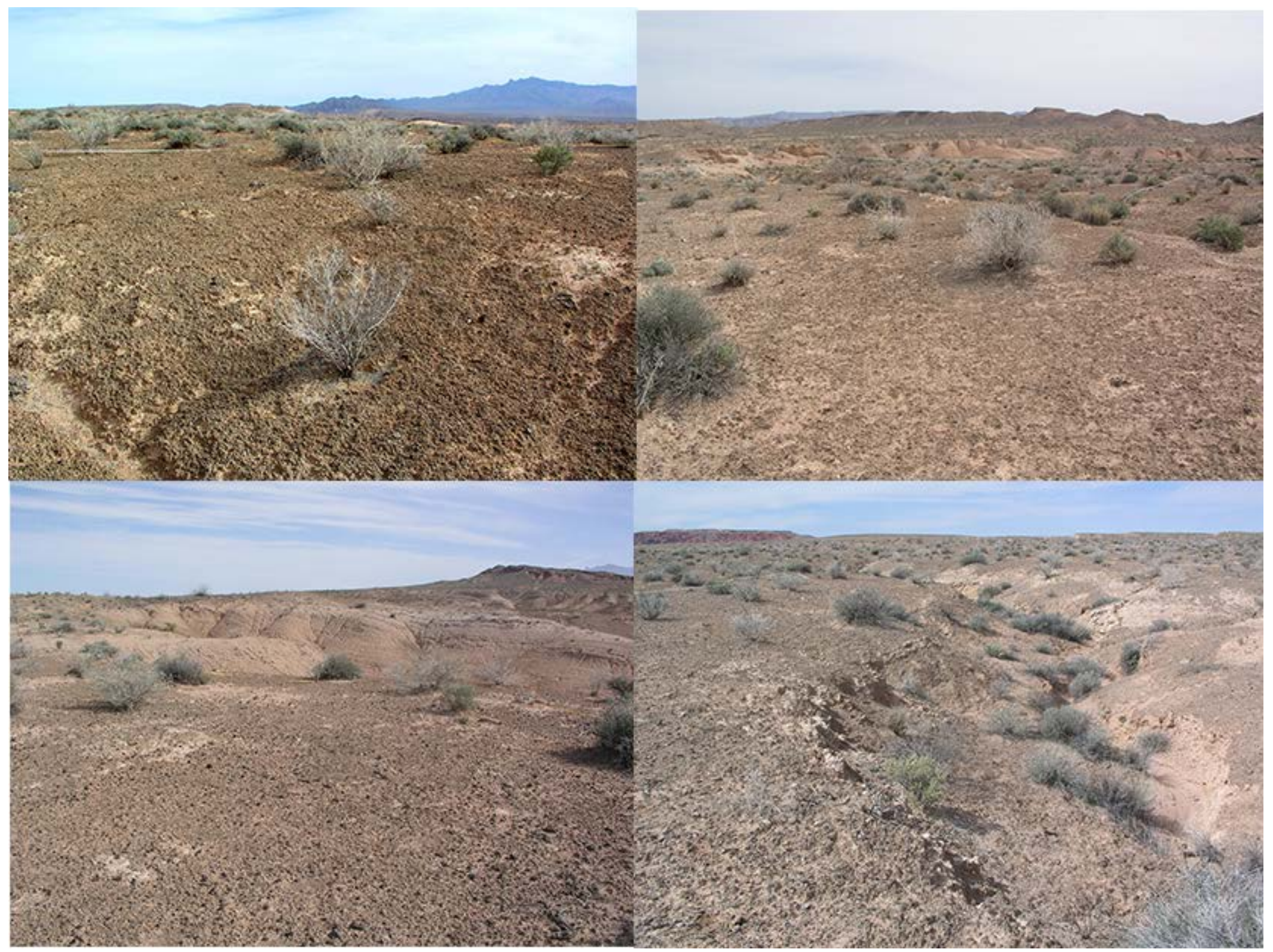

Fig. S1. Examples of gypsiferous soil communities along Northshore Rd, Lake Mead National Recreation Area, eastern Mojave Desert, USA. Soil crust cover can range from 10-80 \%. Vegetation cover can range from 4-10 \%. Photographs by L. P. Chiquoine. 


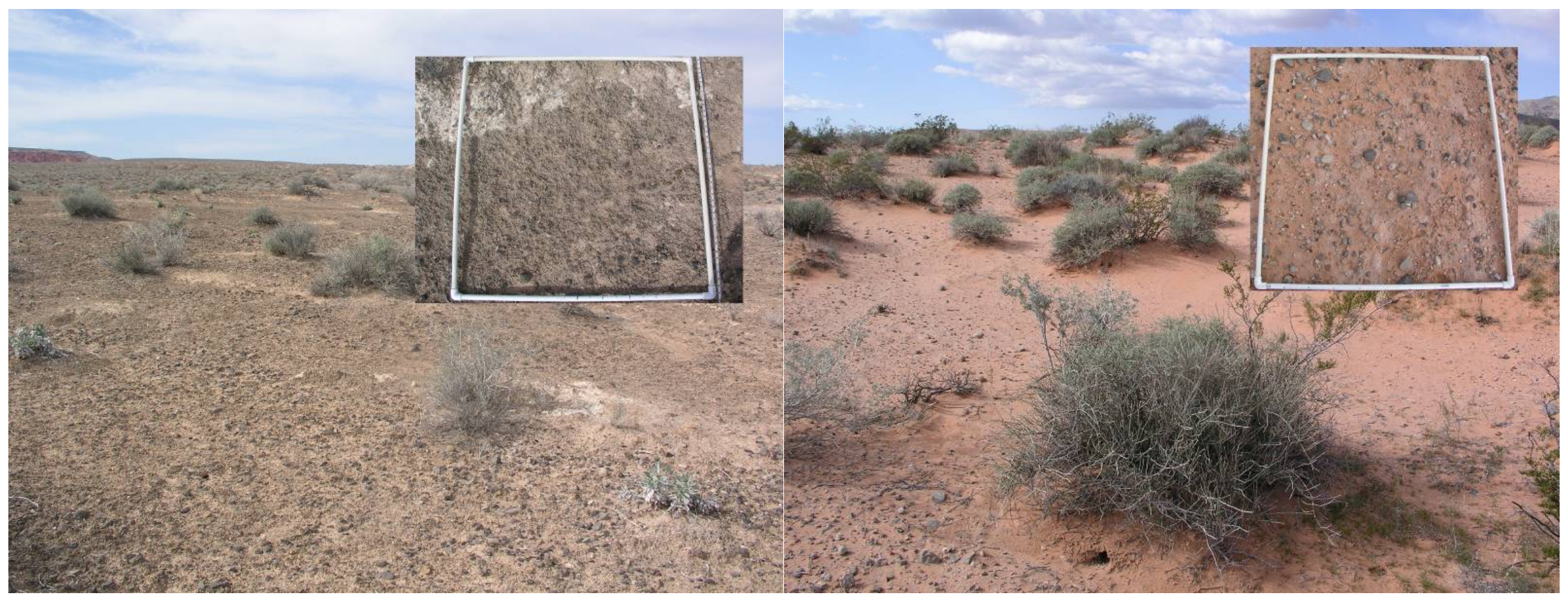

Fig. S2. Undisturbed biocrust and vascular plant communities in gypsiferous (left) and alluvial non-gypsiferous (right) soil along Northshore Road, Lake Mead National Recreation Area, eastern Mojave Desert, USA. Vegetation pictured in the gypsiferous soils include Ambrosia dumosa (A. Gray) Payne, Atriplex spp. L., Psorothamnus fremontii (Torr. ex A. Gray) Barneby, and Encelioposis argophylla (D.C. Eaton) A. Nelson. Biocrusts are dominated by the gelatinous cyanolichen, Collema Wigg. Surface material also contains several other lichen and moss species (see Appendix B). Vegetation pictured in the non-gypsiferous sandy soil included A. dumosa and Larrea tridentata (DC.) Coville. Biocrusts in alluvial soils are an incipient or little-developed cyanobacteria crust, and are mostly composed to the filamentous cyanobacteria including Microcoleus sp. Desmaziéres ex Gomont, as well as several other species. Photographs by L. P. Chiquoine. 


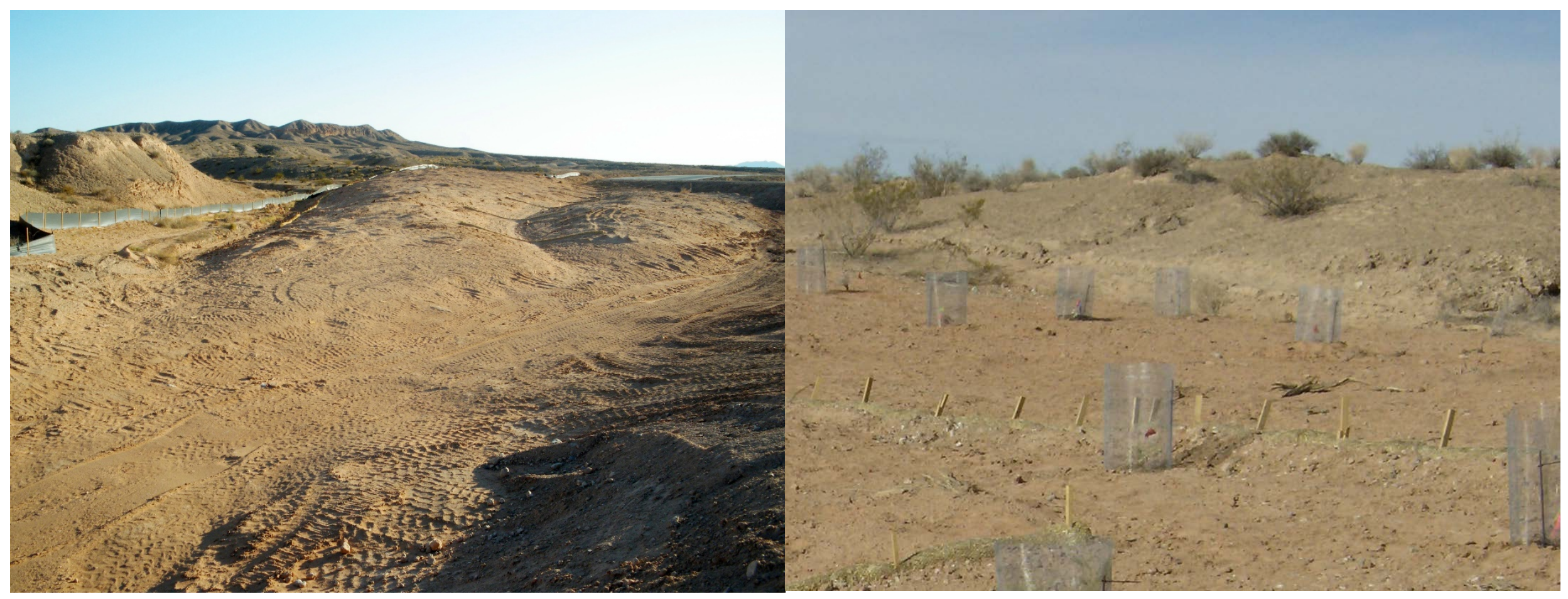

Fig. S3. Images from the Northshore Road realignment project in gypsiferous soils, in the eastern Mojave Desert, USA. (Left) Northshore Road realignment 14 months (December 2009) after construction was completed and salvaged topsoil reapplied to newly contoured surfaces. In the image, topsoil is restricted to the main contoured areas and is not present in the constructed dry wash area. Washes were not included in the study. Surface material was reinforced by straw barriers. (Right) Image of the Northshore Road revegetation project established 15 months after construction disturbance began and one month after topsoil was reapplied to study areas. Planting treatments were assessed in Abella et al. (2015). Ambrosia dumosa shrubs from this project were used as a treatment in our biocrust restoration study. Photographs by L. P. Chiquoine. 
Literature Cited

Abella, S. R., L. P. Chiquoine, A. C. Newton, and C. H. Vanier. 2015. Restoring a desert ecosystem using soil salvage, revegetation, and irrigation. Journal of Arid Environments 115:44-52.

Abella, S. R., K. A. Prengaman, T. M. Embrey, S. M. Schmid, A. C. Newton, and D. J. Merkler. 2012. A hierarchical analysis of vegetation on a Mojave Desert landscape, USA. Journal of Arid Environments 78:135-143. 
Chiquoine, Lindsay P., Scott R. Abella, and Matthew A. Bowker

Rapidly restoring biological soil crusts and ecosystem functions in a severely disturbed desert ecosystem

APPENDIX S2. Supplementary biocrust community composition and treatment analyses results for a biocrust restoration study in the eastern Mojave Desert, USA.

Table S1. Summary of data analyses for biocrust restoration experiment. Not all variables met the assumptions of the proposed model. Therefore, we computed $P$ values and standard errors for means in two ways.

Transformations and computed F statistic and P-values computation method for response variables are listed.

\begin{tabular}{|c|c|c|}
\hline Reponses Variable & Transformation & P-value computational method \\
\hline Lichen cover and lichen species & $\log _{10}+1$ & Permuted \\
\hline Moss cover & $\log _{10}+1$ & Permuted \\
\hline Cyanobacteria density & $\log _{10}+1$ & Normal \\
\hline Soil $\mathrm{NH}_{4}-\mathrm{N}$ & $\log _{10}+1$ & Normal \\
\hline Soil $\mathrm{NO}_{3}-\mathrm{N}$ & $\log _{10}+1$ & Normal \\
\hline Soil chlorophyll a & square root +0.75 & Normal \\
\hline Soil stability & None & Normal \\
\hline Fluorescence & None & Permuted \\
\hline
\end{tabular}



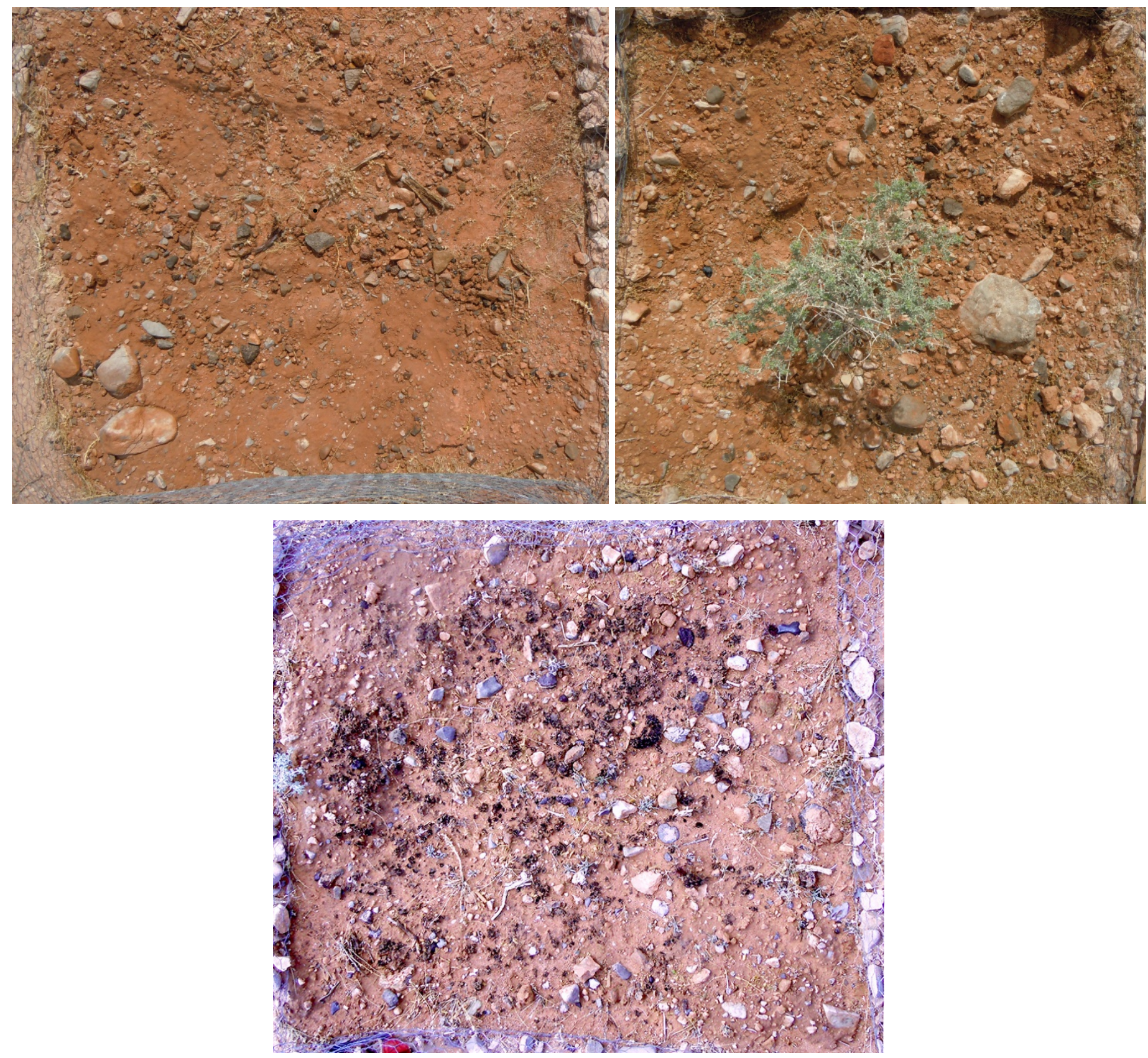

Fig. S1. Examples of surface materials 18 months after establishment of biocrust restoration project treatments in the eastern Mojave Desert, USA. Top left: Topsoil treatment plot, no biocrust inoculation. Topsoil reapplication was completed 14 months after initial disturbance event. Top right: Perennial planting treatment, no biocrust inoculation. Salvaged perennial plants were outplanted 15 months after initial disturbance event. Bottom: Salvaged biocrust inoculation treatment. Salvaged biocrust treatments were applied 25 months after initial disturbance. All plots were watered and surfaces roughened with a hand trowel when plots were established. Photographs by L. P. Chiquoine. 
Supplemental species composition results

\section{Lichen and moss detection}

Lichens occurred in $100 \%$ of inoculated and undisturbed plots and were a significant proportion of the biocrust cover. Mosses occurred in $48 \%$ of inoculated and five out of the six undisturbed plots but had negligible cover at the time of the surveys. Collema Wigg., a gelatinous cyanolichen common in arid and semiarid landscapes, occurred at the highest frequency in all plots containing biocrust and contributed significantly to biocrust cover. Other lichens that contributed to cover but occurred less frequently within plots and across plots included: Placidium squamulosum (Ach.) Breuss, Placidium lacinulatum (Ach.) Breuss, and Peltula patellata (Bagl.) Swinscow \& Krog. Peltula richardsii (Herre) Wet. was also observed in 21 \% of the experimental inoculated plots but at a low frequency and cover and was observed in only one undisturbed plot. Psora decipiens (Hedwig) Hoffm. occurred at a low frequency and cover ( $<1 \%)$ in $13 \%$ of inoculated plots and was not detected in undisturbed plots. Additional lichens with low occurrence and frequency and trace cover within plots included: Aspicilia aspera (Mereschk.) Tomin, Diploschistes diacapsis (Ach.) Lumbsch, and Fulgensia bracteata (Hoffm.) Räsänen. Moss species included Syntrichia caninervis Mitten, Aloina bifrons (De Not.) Delg., Pterygoneurum sp. Jur., Crossidium sp. Jur., Didymodon sp. Hedw., Grimmia sp. Hedw. and Bryum sp. Hedw.

\section{Cyanobacteria detection}

Cyanobacteria species identification using light microscopy can be difficult for some species. Differentiating physical characteristics can be indistinguishable using light microscopy. Additional chemical and genetic studies are often necessary to distinguish some cyanobacteria species. We used existing cyanobacteria research from the Mojave Desert and regionally (Boyer et al. 2002; Alwathnani and Johansen 2011) to identify species most likely present in the soils at our study sites. Unidentified species were counted in total cyanobacteria counts and identified by morphology (filamentous, colonial, and unicellular).

Cyanobacteria were essentially absent from plots not treated with biocrust inoculum or topsoil. The most commonly observed cyanobacteria included Microcoleus sp. Desmaziéres ex Gomont, Phormidium sp. Kützing ex Gomont, Scytonema sp. Agardh ex Bornet et Flahault, Symploca sp. Kützing ex Gomont, Nostoc sp. Vaucher ex Bornet \& Flahault, Leptolygnbya sp. Anagnostidis et Komárek, Pseudophormidium sp. (Forti) Anagnostidis et Komárek, Hassallia sp. Berkeley ex Bornet et Flahault, and Tolypothrix sp. Kützing ex Bornet et Flahault.

Most detected species were filamentous, and significant effects on filamentous cyanobacteria from treatments followed the same trends as total cyanobacteria (Table S9). However, for non-filamentous cyanobacteria there were additional interactions. Colonial cyanobacteria density, which mostly consisted of Nostoc desertorum Řeháková \& Johansen, was significantly higher in plots with either topsoil or biocrust inoculation compared to plots without these treatments (Fig. S2). Perennial plant or wood shavings had different 
interaction effects for topsoil and biocrust. The addition of a perennial plant to plots with inoculum increased colonial cyanobacteria, while the addition of a perennial plant to plots with topsoil decreased colonial cyanobacteria. For inoculated plots that contained a perennial plant and wood shavings, colonial cyanobacteria was qualitatively decreased. However, for topsoil plots that contained a perennial plant and wood shavings, colonial cyanobacteria was significantly increased.

For unicellular cyanobacteria, there was a three-way interaction between inoculation, topsoil and perennial planting (Fig. S2). Unicellular cyanobacteria density did not differ with the addition of inoculation alone in disturbed plots. However, the addition of either topsoil or perennial planting when biocrust was present significantly increased these cyanobacteria. When both perennial plants and topsoil were together in inoculated plots, unicellular cyanobacteria actually decreased. Without biocrust present, these additional treatments had no significant effect on unicellular cyanobacteria. 
Table S2. Biocrust lichen and moss species composition similarity between treatments in a biocrust restoration experiment in the eastern Mojave Desert, USA. Treatments were implemented as a four-factor design applied factorially and included topsoil reapplication (TS), inoculation with salvaged biocrust (BSC), wood shavings (WS), and perennial planting (PP). Data are percent similarity (Sørensen index) of species composition between treatments.

\begin{tabular}{|c|c|c|c|c|c|c|c|c|c|c|c|c|c|c|c|c|}
\hline & BSC & TS & WS & PP & $\mathrm{BSC} \times \mathrm{WS}$ & $\mathrm{BSC} \times \mathrm{PP}$ & TS $\times W S$ & $\mathrm{TS} \times \mathrm{PP}$ & WS $\times P P$ & $B S C \times T S \times W S$ & $\mathrm{BSC} \times \mathrm{TS} \times \mathrm{PP}$ & $B S C \times W S \times P P$ & $T S \times W S \times P P$ & $B S C \times T S \times W S \times P P$ & $\begin{array}{l}\text { Disturbed, } \\
\text { no } \\
\text { treatment }\end{array}$ & $\begin{array}{l}\text { Undisturbed } \\
\text { reference }\end{array}$ \\
\hline Biological soil crust (BSC) & 100 & 0 & 0 & 0 & 89 & 67 & 0 & 0 & 0 & 87 & 60 & 69 & 0 & 78 & 0 & 68 \\
\hline Topsoil reapplication (TS) & 0 & 100 & 100 & 100 & 0 & 0 & 100 & 100 & 100 & 0 & 0 & 0 & 100 & 0 & 100 & 0 \\
\hline Wood shavings (WS) & 0 & 100 & 100 & 100 & 0 & 0 & 100 & 100 & 100 & 0 & 0 & 0 & 100 & 0 & 100 & 0 \\
\hline Perennial Plant (PP) & 0 & 100 & 100 & 100 & 0 & 0 & 100 & 100 & 100 & 0 & 0 & 0 & 100 & 0 & 100 & 0 \\
\hline $\mathrm{BSC} \times \mathrm{TS}$ & 74 & 0 & 0 & 0 & 73 & 94 & 0 & 0 & 0 & 69 & 83 & 95 & 0 & 56 & 0 & 89 \\
\hline BSC $\times W S$ & 89 & 0 & 0 & 0 & 100 & 66 & 0 & 0 & 0 & 88 & 62 & 68 & 0 & 79 & 0 & 71 \\
\hline $\mathrm{BSC} \times \mathrm{PP}$ & 67 & 0 & 0 & 0 & 66 & 100 & 0 & 0 & 0 & 63 & 86 & 98 & 0 & 50 & 0 & 87 \\
\hline TS $\times W S$ & 0 & 100 & 100 & 100 & 0 & 0 & 100 & 100 & 100 & 0 & 0 & 0 & 100 & 0 & 100 & 0 \\
\hline $\mathrm{TS} \times \mathrm{PP}$ & 0 & 100 & 100 & 100 & 0 & 0 & 100 & 100 & 100 & 0 & 0 & 0 & 100 & 0 & 100 & 0 \\
\hline WS $\times P P$ & 0 & 100 & 100 & 100 & 0 & 0 & 100 & 100 & 100 & 0 & 0 & 0 & 100 & 0 & 100 & 0 \\
\hline$B S C \times T S \times W S$ & 87 & 0 & 0 & 0 & 88 & 63 & 0 & 0 & 0 & 100 & 56 & 64 & 0 & 87 & 0 & 64 \\
\hline $\mathrm{BSC} \times \mathrm{TS} \times \mathrm{PP}$ & 60 & 0 & 0 & 0 & 62 & 86 & 0 & 0 & 0 & 56 & 100 & 87 & 0 & 51 & 0 & 91 \\
\hline $\mathrm{BSC} \times W S \times P P$ & 69 & 0 & 0 & 0 & 68 & 98 & 0 & 0 & 0 & 64 & 87 & 100 & 0 & 52 & 0 & 89 \\
\hline$T S \times W S \times P P$ & 0 & 100 & 100 & 100 & 0 & 0 & 100 & 100 & 100 & 0 & 0 & 0 & 100 & 0 & 100 & 0 \\
\hline$B S C \times T S \times W S \times P P$ & 78 & 0 & 0 & 0 & 79 & 50 & 0 & 0 & 0 & 87 & 51 & 52 & 0 & 100 & 0 & 58 \\
\hline Disturbed, no treatment & 0 & 100 & 100 & 100 & 0 & 0 & 100 & 100 & 100 & 0 & 0 & 0 & 100 & 0 & 100 & 0 \\
\hline Undisturbed reference & 68 & 0 & 0 & 0 & 71 & 87 & 0 & 0 & 0 & 64 & 91 & 89 & 0 & 58 & 0 & 100 \\
\hline
\end{tabular}


Table S3. Biocrust cyanobacteria species composition similarity between treatments in a biocrust restoration experiment in the eastern Mojave Desert, USA. Treatments were implemented as a four-factor design applied factorially and included topsoil reapplication (TS), inoculation with salvaged biocrust (BSC), wood shavings (WS), and perennial planting (PP). Data are percent similarity (Sørensen index) of species composition between treatments.

\begin{tabular}{|c|c|c|c|c|c|c|c|c|c|c|c|c|c|c|c|c|c|}
\hline & BSC & TS & WS & PP & $\mathrm{BSC} \times \mathrm{TS}$ & $\mathrm{BSC} \times \mathrm{WS}$ & $\mathrm{BSC} \times \mathrm{PP}$ & TS $\times$ WS & $T S \times P P$ & WS $\times P P$ & $B S C \times T S \times W S$ & $\mathrm{BSC} \times \mathrm{TS} \times \mathrm{PP}$ & $\mathrm{BSC} \times \mathrm{WS} \times \mathrm{PP}$ & $T S \times W S \times P P$ & $B S C \times T S \times W S \times P P$ & $\begin{array}{c}\text { Disturbed, } \\
\text { no } \\
\text { treatment }\end{array}$ & $\begin{array}{l}\text { Undisturbed } \\
\text { reference }\end{array}$ \\
\hline Biological soil crust (BSC) & 100 & 53 & 0 & 0 & 63 & 70 & 54 & 43 & 42 & 0 & 48 & 69 & 59 & 47 & 48 & 0 & 53 \\
\hline Topsoil reapplication (TS) & 53 & 100 & 0 & 0 & 57 & 56 & 37 & 57 & 77 & 0 & 38 & 63 & 39 & 67 & 29 & 0 & 40 \\
\hline Wood shavings (WS) & 0 & 0 & 100 & 0 & 2 & 1 & 0 & 0 & 0 & 0 & 2 & 3 & 0 & 0 & 4 & 0 & 8 \\
\hline Perennial Plant (PP) & 0 & 0 & 0 & 100 & 0 & 0 & 0 & 0 & 0 & 100 & 0 & 0 & 0 & 0 & 0 & 100 & 0 \\
\hline $\mathrm{BSC} \times \mathrm{TS}$ & 63 & 57 & 2 & 0 & 100 & 83 & 64 & 43 & 49 & 0 & 66 & 57 & 75 & 54 & 55 & 0 & 64 \\
\hline $\mathrm{BSC} \times \mathrm{WS}$ & 70 & 56 & 1 & 0 & 83 & 100 & 53 & 34 & 48 & 0 & 54 & 58 & 63 & 53 & 53 & 0 & 54 \\
\hline $\mathrm{BSC} \times \mathrm{PP}$ & 54 & 37 & 0 & 0 & 64 & 53 & 100 & 34 & 31 & 0 & 87 & 62 & 79 & 31 & 66 & 0 & 75 \\
\hline TS $\times$ WS & 43 & 57 & 0 & 0 & 43 & 34 & 34 & 100 & 77 & 0 & 30 & 44 & 33 & 42 & 19 & 0 & 33 \\
\hline$T S \times P P$ & 42 & 77 & 0 & 0 & 49 & 48 & 31 & 77 & 100 & 0 & 30 & 52 & 40 & 65 & 27 & 0 & 34 \\
\hline WS $\times P P$ & 0 & 0 & 0 & 100 & 0 & 0 & 0 & 0 & 0 & 100 & 0 & 0 & 0 & 0 & 0 & 100 & 0 \\
\hline$B S C \times T S \times W S$ & 48 & 38 & 2 & 0 & 66 & 54 & 87 & 30 & 30 & 0 & 100 & 62 & 74 & 30 & 66 & 0 & 79 \\
\hline $\mathrm{BSC} \times \mathrm{TS} \times \mathrm{PP}$ & 69 & 63 & 3 & 0 & 57 & 58 & 62 & 44 & 52 & 0 & 62 & 100 & 58 & 51 & 58 & 0 & 63 \\
\hline $\mathrm{BSC} \times W S \times P P$ & 59 & 39 & 0 & 0 & 75 & 63 & 79 & 33 & 40 & 0 & 74 & 58 & 100 & 42 & 66 & 0 & 70 \\
\hline$T S \times W S \times P P$ & 47 & 67 & 0 & 0 & 54 & 53 & 31 & 42 & 65 & 0 & 30 & 51 & 42 & 100 & 28 & 0 & 34 \\
\hline$B S C \times T S \times W S \times P P$ & 48 & 29 & 4 & 0 & 55 & 53 & 66 & 19 & 27 & 0 & 66 & 58 & 66 & 28 & 100 & 0 & 69 \\
\hline Disturbed, no treatment & 0 & 0 & 0 & 100 & 0 & 0 & 0 & 0 & 0 & 100 & 0 & 0 & 0 & 0 & 0 & 100 & 0 \\
\hline Undisturbed reference & 53 & 40 & 8 & 0 & 64 & 54 & 75 & 33 & 34 & 0 & 79 & 63 & 70 & 34 & 69 & 0 & 100 \\
\hline
\end{tabular}


Table S4. Effects of treatments, inoculation with salvaged biological soil crust (BSC), topsoil reapplication (TS), wood shavings (WS), and perennial planting (PP) and all their interactions, on total lichen and moss cover in a biocrust restoration experiment in the eastern Mojave Desert, USA. Topsoil reapplication and perennial planting occurred 14 and 15 months, respectively, after initial construction disturbance, and experimental plots were established 25 months after initial disturbance. All plots were assessed 18 months after experimental plot establishment. DF is numerator and denominator degrees of freedom. Pseudo-F and permuted P value for cover variables in permutational multivariate analysis of variance. Significant values with $\mathrm{P}<0.05$ are in bold.

\begin{tabular}{|c|c|c|c|c|c|c|}
\hline \multirow[b]{2}{*}{ Source of variation } & \multicolumn{3}{|c|}{ Lichen Cover } & \multicolumn{3}{|c|}{ Moss Cover } \\
\hline & $\mathrm{F}$ & DF & $\mathrm{P}$ & $\mathrm{F}$ & DF & $\mathrm{P}$ \\
\hline Biological soil crust (BSC) & 18.14 & 1,13 & 0.002 & 9.89 & 1,13 & 0.003 \\
\hline Topsoil reapplication (TS) & 0.01 & 1,13 & 0.928 & 0.23 & 1,13 & 0.801 \\
\hline Wood shavings (WS) & 0.00 & 1,13 & 0.995 & 0.71 & 1,13 & 0.470 \\
\hline Perennial Plant (PP) & 0.01 & 1,13 & 0.956 & 0.43 & 1,13 & 0.677 \\
\hline BSC $\times$ TS & 0.00 & 1,13 & 0.990 & 0.19 & 1,13 & 0.839 \\
\hline BSC $\times W S$ & 0.00 & 1,13 & 0.995 & 1.12 & 1,13 & 0.337 \\
\hline $\mathrm{BSC} \times \mathrm{PP}$ & 0.00 & 1,13 & 0.989 & 0.35 & 1,13 & 0.693 \\
\hline TS $\times W S$ & 0.00 & 1,13 & 0.998 & 0.18 & 1,13 & 0.797 \\
\hline TS $\times P P$ & 0.00 & 1,13 & 1.000 & 0.48 & 1,13 & 0.603 \\
\hline WS $\times P P$ & 0.00 & 1,13 & 0.987 & 0.08 & 1,13 & 0.937 \\
\hline BSC $\times$ TS $\times W S$ & 0.00 & 1,13 & 0.997 & 0.30 & 1,13 & 0.747 \\
\hline $\mathrm{BSC} \times \mathrm{TS} \times \mathrm{PP}$ & 0.00 & 1,13 & 1.000 & 0.39 & 1,13 & 0.679 \\
\hline$B S C \times W S \times P P$ & 0.00 & 1,13 & 0.989 & 0.08 & 1,13 & 0.937 \\
\hline TS $\times W S \times P P$ & 0.00 & 1,13 & 0.997 & 0.06 & 1,13 & 0.964 \\
\hline BSC $\times T S \times W S \times P P$ & 0.00 & 1,13 & 0.999 & 0.06 & 1,13 & 0.960 \\
\hline
\end{tabular}


Table S5. Effects of treatments, inoculation with salvaged biological soil crust (BSC), topsoil reapplication (TS), wood shavings (WS), and perennial planting (PP) and all their interactions, on dominant soil lichen species cover in a biocrust restoration experiment in the eastern Mojave Desert, USA. Topsoil reapplication and perennial planting occurred 14 and 15 months, respectively, after initial construction disturbance, and experimental plots were established 25 months after initial disturbance. All plots were assessed 18 months after experimental plot establishment. DF is numerator and denominator degrees of freedom. Pseudo-F and permuted $\mathrm{P}$ value for cover variables in permutational multivariate analysis of variance. Significant values with $\mathrm{P}<0.05$ are in bold.

\begin{tabular}{|c|c|c|c|c|c|c|c|}
\hline \multirow[b]{2}{*}{ Source of variation } & \multirow[b]{2}{*}{ DF } & \multicolumn{2}{|c|}{ Collema } & \multicolumn{2}{|c|}{ Placidium } & \multicolumn{2}{|c|}{ Peltula } \\
\hline & & $\mathrm{F}$ & $P$ & $\mathrm{~F}$ & $P$ & $\mathrm{~F}$ & $P$ \\
\hline Biological soil crust (BSC) & 1,16 & 18.12 & 0.002 & 17.71 & 0.001 & 16.86 & 0.001 \\
\hline Topsoil reapplication (TS) & 1,16 & 0.00 & 0.992 & 0.15 & 0.821 & 0.19 & 0.844 \\
\hline Wood shavings (WS) & 1,16 & 0.00 & 0.989 & 0.45 & 0.564 & 0.10 & 0.927 \\
\hline Perennial Plant (PP) & 1,16 & 0.05 & 0.839 & 0.03 & 0.978 & 0.09 & 0.837 \\
\hline BSC $\times$ TS & 1,16 & 0.00 & 1.000 & 0.06 & 0.957 & 0.09 & 0.941 \\
\hline BSC $\times W S$ & 1,16 & 0.00 & 0.988 & 0.45 & 0.580 & 0.08 & 0.943 \\
\hline $\mathrm{BSC} \times \mathrm{PP}$ & 1,16 & 0.01 & 0.949 & 0.01 & 0.998 & 0.02 & 0.995 \\
\hline TS $\times$ WS & 1,16 & 0.01 & 0.958 & 0.24 & 0.745 & 0.06 & 0.966 \\
\hline TS $\times P P$ & 1,16 & 0.00 & 0.984 & 0.32 & 0.673 & 1.85 & 0.169 \\
\hline WS $\times P P$ & 1,16 & 0.00 & 1.000 & 0.06 & 0.948 & 0.23 & 0.810 \\
\hline BSC $\times$ TS $\times W S$ & 1,16 & 0.01 & 0.951 & 0.26 & 0.722 & 0.05 & 0.984 \\
\hline BSC $\times T S \times P P$ & 1,16 & 0.00 & 0.995 & 0.08 & 0.928 & 0.46 & 0.611 \\
\hline$B S C \times W S \times P P$ & 1,16 & 0.00 & 1.000 & 0.04 & 0.977 & 0.13 & 0.908 \\
\hline TS $\times W S \times P P$ & 1,16 & 0.01 & 0.968 & 0.22 & 0.763 & 0.10 & 0.930 \\
\hline$B S C \times T S \times W S \times P P$ & 1,16 & 0.00 & 0.987 & 0.14 & 0.854 & 0.05 & 0.972 \\
\hline
\end{tabular}


Table S6. Pairwise contrasts between undisturbed reference plots and experimental field plots for biocrust cover (sum of lichen and moss cover) observed in a biocrust restoration experiment in the eastern Mojave Desert, USA. Experimental field treatments include disturbance (removal of soil surface materials), topsoil reapplication (TS), inoculation with salvaged biological soil crust (BSC), wood shavings (WS), and perennial planting (PP). Topsoil reapplication and perennial planting occurred 14 and 15 months, respectively, after initial construction disturbance, and experimental plots were established 25 months after initial disturbance. All plots were assessed 18 months after experimental plot establishment. Undisturbed plots were included in the overall model to contribute to total variance, but were excluded from consideration in main effects and interactions in model. Pseudo-F and permuted P value for biocrust cover represent the comparison between undisturbed plots and experimental field treatments and all their interactions set as fixed effects, calculated with permutational multivariate analysis of variance. DF is numerator and denominator degrees of freedom. Significant values $\mathrm{P}<0.05$ in bold.

\begin{tabular}{|c|c|c|c|}
\hline \multirow[b]{2}{*}{ Effect } & \multicolumn{3}{|c|}{ Biocrust Cover } \\
\hline & $\mathrm{F}$ & DF & $P$ \\
\hline Biological soil crust (BSC) & 0.39 & 1,18 & 0.777 \\
\hline Topsoil reapplication (TS) & 4.60 & 1,18 & 0.008 \\
\hline Wood shavings (WS) & 4.99 & 1,18 & 0.006 \\
\hline Perennial Plant (PP) & 4.78 & 1,18 & 0.007 \\
\hline BSC $\times$ TS & 0.70 & 1,18 & 0.586 \\
\hline BSC $\times W S$ & 0.90 & 1,18 & 0.449 \\
\hline $\mathrm{BSC} \times \mathrm{PP}$ & 0.67 & 1,18 & 0.604 \\
\hline TS $\times$ WS & 5.31 & 1,18 & 0.005 \\
\hline TS $\times P P$ & 4.61 & 1,18 & 0.008 \\
\hline WS $\times P P$ & 5.05 & 1,18 & 0.009 \\
\hline $\mathrm{BSC} \times \mathrm{TS} \times \mathrm{WS}$ & 0.86 & 1,18 & 0.483 \\
\hline BSC $\times$ TS $\times P P$ & 0.57 & 1,18 & 0.663 \\
\hline $\mathrm{BSC} \times \mathrm{WS} \times \mathrm{PP}$ & 0.96 & 1,18 & 0.427 \\
\hline TS $\times W S \times P P$ & 4.86 & 1,18 & 0.007 \\
\hline$B S C \times T S \times W S \times P P$ & 0.79 & 1,18 & 0.531 \\
\hline Disturbance, no treatment & 4.69 & 1,18 & 0.008 \\
\hline
\end{tabular}


Table S7. Effects of treatments, inoculation with salvaged biological soil crust (BSC), topsoil reapplication (TS), wood shavings (WS), and perennial planting (PP) and all their interactions, on total soil cyanobacteria density in a biocrust restoration experiment in the eastern Mojave Desert, USA. Topsoil reapplication and perennial planting occurred 14 and 15 months, respectively, after initial construction disturbance, and experimental plots were established 25 months after initial disturbance. All plots were assessed 18 months after experimental plot establishment. DF is the numerator and denominator degrees of freedom. F-statistic and $\mathrm{P}$ value for cyanobacteria density calculated with permutational multivariate analysis of variance. Significant values $\mathrm{P}<0.05$ in bold.

\begin{tabular}{|c|c|c|c|}
\hline \multirow[b]{2}{*}{ Source of variation } & \multicolumn{3}{|c|}{ Cyanobacteria Density } \\
\hline & $\mathrm{F}$ & DF & $\mathrm{P}$ \\
\hline Biological soil crust (BSC) & 216.24 & 1,16 & 0.000 \\
\hline Topsoil reapplication (TS) & 8.71 & 1,16 & 0.009 \\
\hline Wood shavings (WS) & 1.19 & 1,16 & 0.291 \\
\hline Perennial Plant (PP) & 1.31 & 1,16 & 0.269 \\
\hline BSC $\times$ TS & 6.98 & 1,16 & 0.018 \\
\hline BSC $\times W S$ & 0.69 & 1,16 & 0.419 \\
\hline$B S C \times P P$ & 1.60 & 1,16 & 0.225 \\
\hline TS $\times W S$ & 0.04 & 1,16 & 0.846 \\
\hline TS $\times P P$ & 0.56 & 1,16 & 0.464 \\
\hline WS $\times P P$ & 0.29 & 1,16 & 0.601 \\
\hline BSC $\times$ TS $\times W S$ & 0.07 & 1,16 & 0.789 \\
\hline BSC $\times T S \times P P$ & 0.04 & 1,16 & 0.839 \\
\hline$B S C \times W S \times P P$ & 0.00 & 1,16 & 0.992 \\
\hline$T S \times W S \times P P$ & 0.24 & 1,16 & 0.633 \\
\hline BSC $\times T S \times W S \times P P$ & 0.19 & 1,16 & 0.666 \\
\hline
\end{tabular}


Table S8. Pairwise contrasts between undisturbed reference plots and experimental field plots for soil cyanobacteria density measured in a biocrust restoration experiment in the eastern Mojave Desert, USA.

Experimental field treatments include disturbance (removal of soil surface materials), topsoil reapplication (TS), inoculation with salvaged biological soil crust (BSC), wood shavings (WS), and perennial planting (PP). Topsoil reapplication and perennial planting occurred 14 and 15 months, respectively, after initial construction disturbance, and experimental plots were established 25 months after initial disturbance. All plots were assessed 18 months after experimental plot establishment. Undisturbed plots were included in the overall model to contribute to total variance, but were excluded from consideration in main effects and interactions in model. F statistic and $\mathrm{P}$ values represent the comparison between undisturbed plots and experimental field treatments and all their interactions, set as fixed effects. DF is numerator and denominator degrees of freedom. Significant values $\mathrm{P}<0.05$ in bold.

\begin{tabular}{|c|c|c|c|}
\hline \multirow[b]{2}{*}{ Effect } & \multicolumn{3}{|c|}{ Cyanobacteria Density } \\
\hline & $F$ & DF & $P$ \\
\hline Biological soil crust (BSC) & 0.04 & 1,16 & 0.849 \\
\hline Topsoil reapplication (TS) & 16.12 & 1,16 & 0.001 \\
\hline Wood shavings (WS) & 30.73 & 1,16 & 0.000 \\
\hline Perennial Plant (PP) & 43.87 & 1,16 & 0.000 \\
\hline BSC $\times$ TS & 0.03 & 1,16 & 0.867 \\
\hline BSC $\times W S$ & 0.02 & 1,16 & 0.881 \\
\hline $\mathrm{BSC} \times \mathrm{PP}$ & 0.07 & 1,16 & 0.788 \\
\hline TS $\times$ WS & 10.73 & 1,16 & 0.005 \\
\hline TS $\times P P$ & 29.35 & 1,16 & 0.000 \\
\hline WS $\times P P$ & 43.87 & 1,16 & 0.000 \\
\hline $\mathrm{BSC} \times \mathrm{TS} \times \mathrm{WS}$ & 0.16 & 1,16 & 0.696 \\
\hline $\mathrm{BSC} \times \mathrm{TS} \times \mathrm{PP}$ & 0.04 & 1,16 & 0.847 \\
\hline $\mathrm{BSC} \times \mathrm{WS} \times \mathrm{PP}$ & 0.03 & 1,16 & 0.860 \\
\hline TS $\times W S \times P P$ & 19.16 & 1,16 & 0.000 \\
\hline BSC $\times T S \times W S \times P P$ & 0.01 & 1,16 & 0.937 \\
\hline Disturbance, no treatment & 43.87 & 1,16 & 0.000 \\
\hline
\end{tabular}


Table S9. Effects of treatments, inoculation with salvaged biological soil crust (BSC), topsoil reapplication (TS), wood shavings (WS), and perennial planting (PP), on three cyanobacteria morphologies in a biocrust restoration experiment in the eastern Mojave Desert, USA. Topsoil reapplication and perennial planting occurred 14 and 15 months, respectively, after initial construction disturbance, and experimental plots were established 25 months after initial disturbance. All plots were assessed 18 months after experimental plot establishment. DF is numerator and denominator degrees of freedom. F-statistic and P value for density analyzed in an analysis of variance model. Significant values $\mathrm{P}<0.05$ in bold.

\begin{tabular}{|c|c|c|c|c|c|c|c|}
\hline \multirow[b]{3}{*}{ Source of variation } & \multirow[b]{3}{*}{ DF } & \multicolumn{4}{|c|}{ Cyanobacteria by morphology } & & \\
\hline & & \multicolumn{2}{|c|}{ Filamentous } & \multicolumn{2}{|c|}{ Colonial } & \multicolumn{2}{|c|}{ Unicellular } \\
\hline & & $\mathrm{F}$ & $\mathrm{P}$ & $\mathrm{F}$ & $\mathrm{P}$ & $\mathrm{F}$ & $\mathrm{P}$ \\
\hline Biological soil crust (BSC) & 1,16 & 209.81 & 0.000 & 180.40 & 0.000 & 96.58 & 0.000 \\
\hline Topsoil reapplication (TS) & 1,16 & 6.80 & 0.019 & 17.29 & 0.001 & 2.40 & 0.141 \\
\hline Wood shavings (WS) & 1,16 & 0.24 & 0.628 & 4.06 & 0.061 & 0.05 & 0.827 \\
\hline Perennial Plant (PP) & 1,16 & 3.43 & 0.082 & 2.32 & 0.147 & 0.13 & 0.723 \\
\hline $\mathrm{BSC} \times \mathrm{TS}$ & 1,16 & 5.50 & 0.032 & 0.01 & 0.913 & 0.93 & 0.350 \\
\hline BSC $\times$ WS & 1,16 & 0.61 & 0.447 & 8.69 & 0.009 & 0.65 & 0.431 \\
\hline$B S C \times P P$ & 1,16 & 1.86 & 0.192 & 0.81 & 0.382 & 0.90 & 0.358 \\
\hline TS $\times$ WS & 1,16 & 0.06 & 0.810 & 6.91 & 0.018 & 0.25 & 0.623 \\
\hline TS $\times P P$ & 1,16 & 0.57 & 0.462 & 1.27 & 0.277 & 10.49 & 0.005 \\
\hline WS $\times P P$ & 1,16 & 1.03 & 0.326 & 0.03 & 0.866 & 1.21 & 0.288 \\
\hline $\mathrm{BSC} \times \mathrm{TS} \times \mathrm{WS}$ & 1,16 & 0.00 & 0.991 & 2.88 & 0.109 & 0.01 & 0.933 \\
\hline BSC $\times$ TS $\times P P$ & 1,16 & 0.91 & 0.354 & 3.07 & 0.099 & 7.04 & 0.017 \\
\hline$B S C \times W S \times P P$ & 1,16 & 0.11 & 0.741 & 7.08 & 0.017 & 0.26 & 0.614 \\
\hline TS $\times W S \times P P$ & 1,16 & 0.00 & 0.958 & 6.67 & 0.020 & 0.07 & 0.790 \\
\hline BSC $\times T S \times W S \times P P$ & 1,16 & 0.01 & 0.919 & 0.01 & 0.926 & 0.10 & 0.756 \\
\hline
\end{tabular}


Table S10. Pairwise contrasts between undisturbed plots and experimental plots for filamentous, colonial, and unicellular cyanobacteria density in a biocrust restoration experiment in the eastern Mojave Desert, USA.

Experimental field treatments include disturbance (removal of soil surface materials), topsoil reapplication (TS), inoculation with salvaged biological soil crust (BSC), wood shavings (WS), and perennial planting (PP).

Topsoil reapplication and perennial planting occurred 14 and 15 months, respectively, after initial construction disturbance, and experimental plots were established 25 months after initial disturbance. All plots were assessed 18 months after experimental plot establishment. Undisturbed plots were included in the overall model to contribute to total variance, but were excluded from consideration in main effects and interactions in model. F statistic and $\mathrm{P}$ values represent the comparison between undisturbed plots and experimental field treatments and all their interactions, set as fixed effects. DF is numerator and denominator degrees of freedom. Significant values $\mathrm{P}<0.05$ in bold.

\begin{tabular}{|c|c|c|c|c|c|c|c|}
\hline \multirow[b]{3}{*}{ Effect } & \multirow[b]{3}{*}{ DF } & \multicolumn{4}{|c|}{ Cyanobacteria by morphology } & & \\
\hline & & \multicolumn{2}{|c|}{ Filamentous } & \multicolumn{2}{|c|}{ Colonial } & \multicolumn{2}{|c|}{ Unicellular } \\
\hline & & $\mathrm{F}$ & $P$ & $\mathrm{~F}$ & $P$ & $\mathrm{~F}$ & $P$ \\
\hline Biological soil crust (BSC) & 1,16 & 0.00 & 0.958 & 26.41 & 0.000 & 0.53 & 0.476 \\
\hline Topsoil reapplication (TS) & 1,16 & 15.08 & 0.001 & 14.52 & 0.002 & 7.02 & 0.018 \\
\hline Wood shavings (WS) & 1,16 & 29.00 & 0.000 & 40.40 & 0.000 & 7.02 & 0.018 \\
\hline Perennial Plant (PP) & 1,16 & 42.35 & 0.000 & 40.40 & 0.000 & 7.02 & 0.018 \\
\hline BSC $\times$ TS & 1,16 & 0.02 & 0.880 & 0.02 & 0.901 & 5.11 & 0.038 \\
\hline BSC $\times W S$ & 1,16 & 0.08 & 0.786 & 0.14 & 0.718 & 0.42 & 0.525 \\
\hline$B S C \times P P$ & 1,16 & 0.00 & 0.976 & 1.25 & 0.281 & 6.60 & 0.021 \\
\hline TS $\times W S$ & 1,16 & 9.31 & 0.008 & 40.40 & 0.000 & 3.16 & 0.095 \\
\hline TS $\times P P$ & 1,16 & 27.80 & 0.000 & 27.01 & 0.000 & 7.02 & 0.018 \\
\hline WS $\times P P$ & 1,16 & 42.35 & 0.000 & 40.40 & 0.000 & 7.02 & 0.018 \\
\hline BSC $\times$ TS $\times W S$ & 1,16 & 0.04 & 0.838 & 0.16 & 0.698 & 6.02 & 0.026 \\
\hline BSC $\times$ TS $\times P P$ & 1,16 & 0.10 & 0.756 & 0.00 & 0.988 & 1.30 & 0.272 \\
\hline$B S C \times W S \times P P$ & 1,16 & 0.05 & 0.833 & 0.08 & 0.776 & 1.99 & 0.177 \\
\hline TS $\times W S \times P P$ & 1,16 & 28.40 & 0.000 & 16.30 & 0.001 & 7.02 & 0.018 \\
\hline$B S C \times T S \times W S \times P P$ & 1,16 & 0.02 & 0.878 & 0.04 & 0.848 & 0.11 & 0.749 \\
\hline Disturbance, no treatment & 1,16 & 42.35 & 0.000 & 40.40 & 0.000 & 7.02 & 0.018 \\
\hline
\end{tabular}



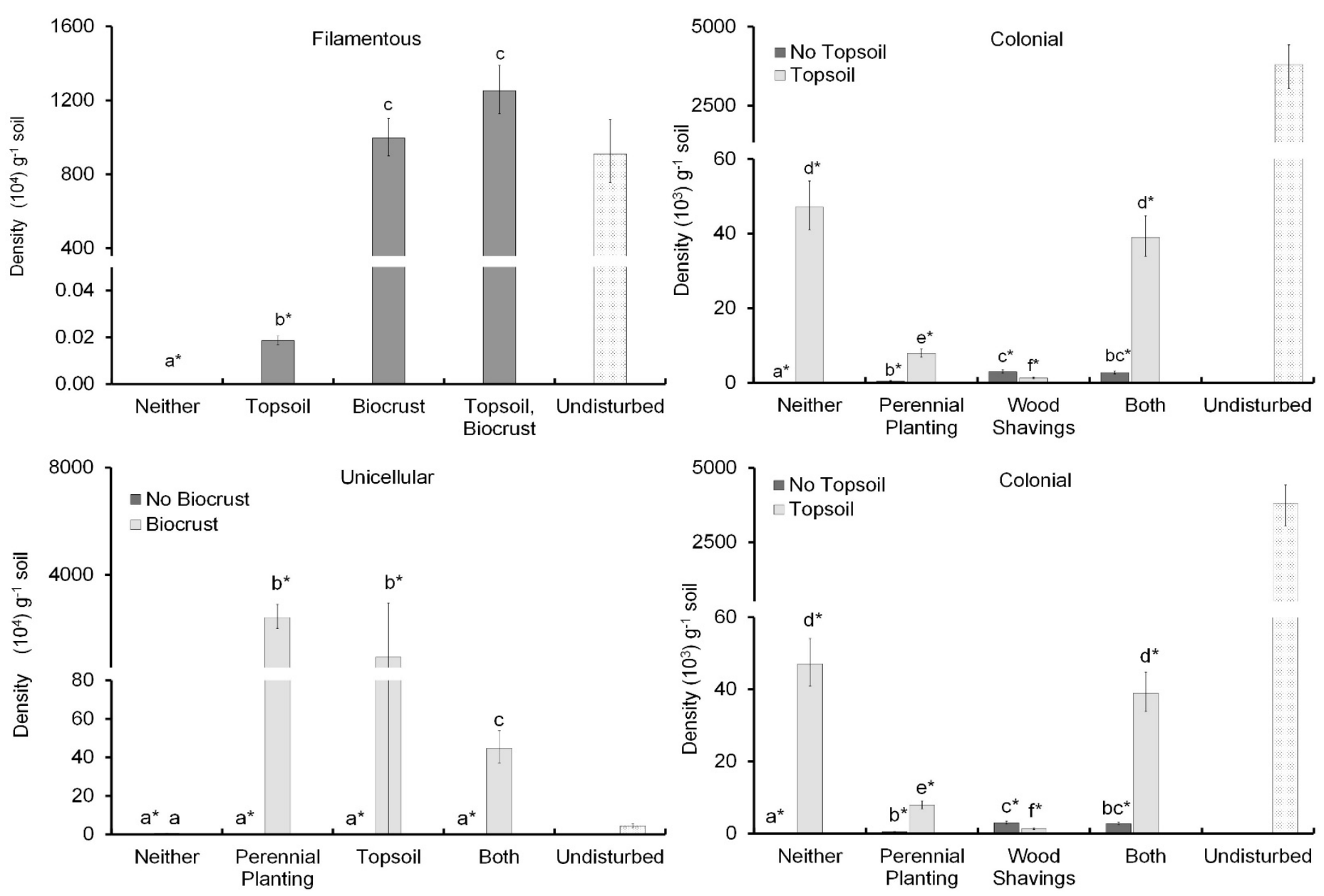

Fig. S2. Significant treatment effects on filamentous (top left), unicellular (bottom left), and colonial (right top and bottom) cyanobacteria morphologies in a biocrust restoration experiment in the eastern Mojave Desert, USA. Topsoil reapplication and perennial planting occurred 14 and 15 months, respectively, after initial construction disturbance, and experimental plots were established 25 months after initial disturbance. All plots were assessed 18 months after experimental plot establishment. Error bars indicate $\pm 1 S E$. Letters denote significance $(\mathrm{P}<0.05)$ among experimental treatments. Asterisks denote treatment difference $(\mathrm{P}<0.05)$ with undisturbed reference plots. 
Table S11. Quantum yield from the soil lichen Collema obtained from disturbed biocrust inoculated plots 18 months after treatment in a biocrust restoration experiment, eastern Mojave Desert, USA. Experimental field treatments include disturbance (removal of soil surface materials), inoculation with salvaged biological soil crust (BSC), topsoil reapplication (TS), wood shavings (WS), and perennial planting (PP). Topsoil reapplication and perennial planting occurred 14 and 15 months, respectively, after initial construction disturbance, and experimental plots were established 25 months after initial disturbance. All plots were assessed 18 months after experimental plot establishment. Quantum yield was limited to treatments with biocrust inoculation and therefore inoculation was not included in the experimental model. Treatment effects were not significant across repeated measures. DF is numerator and denominator degrees of freedom. Significant values with $\mathrm{P}<0.05$ are in bold.

\begin{tabular}{|c|c|c|c|}
\hline \multirow[b]{2}{*}{ Source of variation } & \multicolumn{3}{|c|}{ Quantum yield } \\
\hline & DF & $\mathrm{F}$ & $P$ \\
\hline TIME & 3,48 & 10.52 & 0.0001 \\
\hline Topsoil reapplication (TS) & 1,16 & 0.02 & 0.8960 \\
\hline Wood shavings (WS) & 1,5 & 2.06 & 0.2109 \\
\hline Perennial Plant (PP) & 1,5 & 0.09 & 0.7721 \\
\hline TIMEXTS & 3,48 & 0.82 & 0.4900 \\
\hline TIMEXWS & 3,15 & 0.50 & 0.6905 \\
\hline TIMEXPP & 3,15 & 0.36 & 0.7824 \\
\hline TS $\times W S$ & 1,5 & 0.83 & 0.4035 \\
\hline $\mathrm{TS} \times \mathrm{PP}$ & 1,5 & 3.22 & 0.1326 \\
\hline WS $\times P P$ & 1,5 & 0.00 & 0.9689 \\
\hline TIME $\times$ TS $\times W S$ & 3,15 & 0.47 & 0.7045 \\
\hline TIMEXTS×PP & 3,15 & 1.73 & 0.2038 \\
\hline TIMEXWS×PP & 3,15 & 2.68 & 0.0842 \\
\hline $\mathrm{TS} \times \mathrm{WS} \times \mathrm{PP}$ & 1,5 & 1.51 & 0.2735 \\
\hline TIME×TS×WS×PP & 3,15 & 1.73 & 0.2038 \\
\hline
\end{tabular}




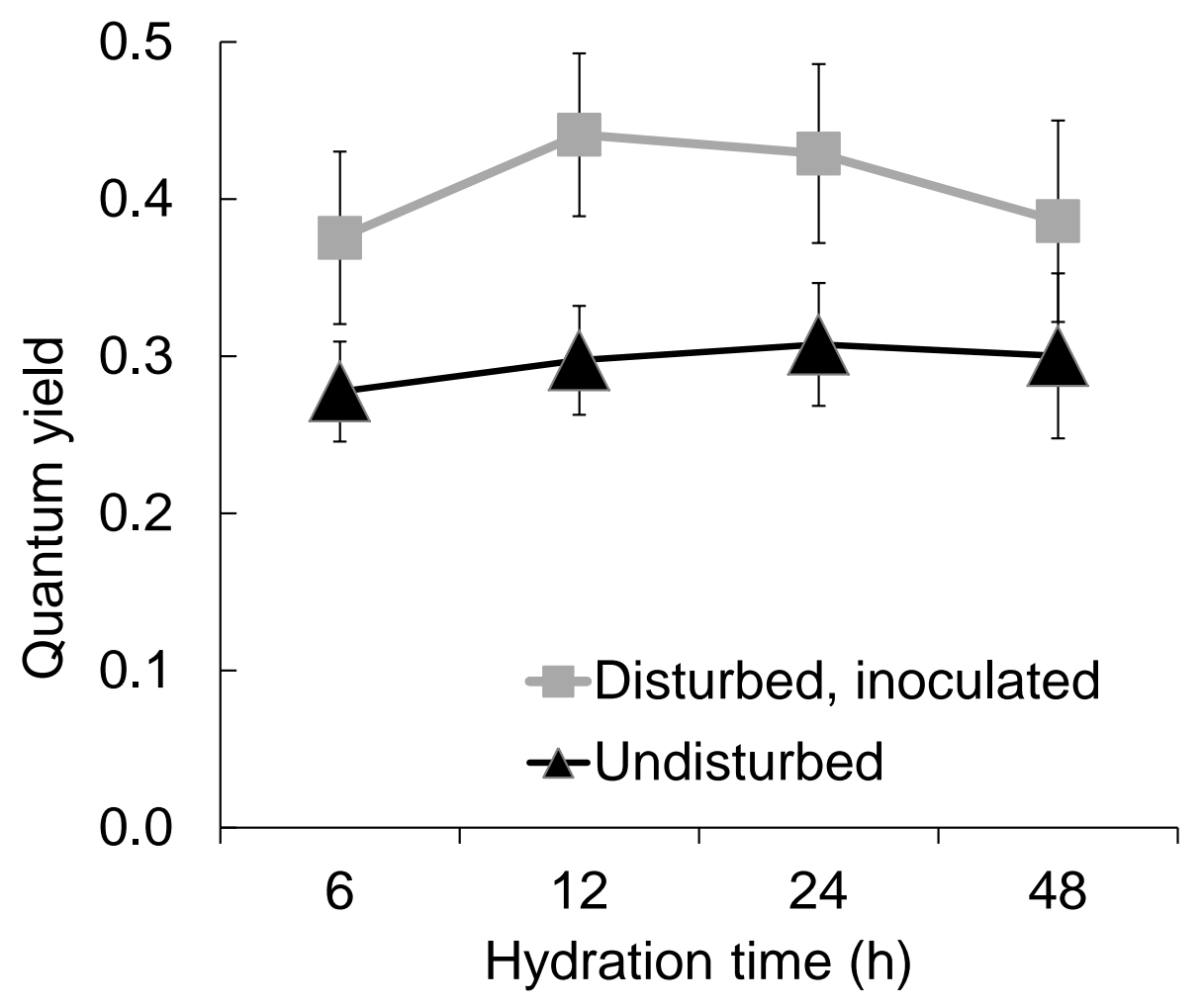

Fig. S3. Fluorescence quantum yield over time from the soil lichen Collema obtained from undisturbed reference plots and disturbed biocrust inoculated plots 18 months after treatment in a biocrust restoration experiment, eastern Mojave Desert, USA. Experimental field treatments include disturbance (removal of soil surface materials), topsoil reapplication, inoculation with salvaged biological soil crust, wood shavings, and perennial planting. Fluorescence varied over time and tended decreased with hydration longer than 12 hours. Fluorescence in undisturbed plots was qualitatively lower than in disturbed treatment plots over the time course. 
Table S12. Effects of treatments, topsoil reapplication (TS), inoculation with salvaged biological soil crust (BSC), wood shavings (WS), and perennial planting (PP), on soil chlorophyll $a$ concentration, soil $\mathrm{NO}_{3}-\mathrm{N}$ and $\mathrm{NH}_{4}-\mathrm{N}$ concentrations, and soil stability in a biocrust restoration experiment in the eastern Mojave Desert, USA. Topsoil reapplication and perennial planting occurred 14 and 15 months, respectively, after initial construction disturbance, and experimental plots were established 25 months after initial disturbance. All plots were assessed 18 months after experimental plot establishment. DF is numerator and denominator degrees of freedom. F-statistic and P value for cover variables calculated with analysis of variance. Significant values $\mathrm{P}<0.05$ in bold.

\begin{tabular}{|c|c|c|c|c|c|c|c|c|c|c|c|c|}
\hline \multirow[b]{2}{*}{ Source of variation } & \multicolumn{3}{|c|}{ Chlorophyll a } & \multicolumn{3}{|c|}{$\mathrm{NO}_{3}-\mathrm{N}$} & \multicolumn{3}{|c|}{$\mathrm{NH}_{4}-\mathrm{N}$} & \multicolumn{3}{|c|}{ Soil Stability } \\
\hline & $\mathrm{F}$ & DF & $P$ & $\mathrm{~F}$ & DF & $P$ & $\mathrm{~F}$ & DF & $\mathrm{P}$ & $\mathrm{F}$ & DF & $P$ \\
\hline Biological soil crust (BSC) & 169.15 & 1,16 & 0.000 & 0.81 & 1,69 & 0.383 & 5.66 & 1,69 & 0.030 & 15.96 & 1,13 & 0.001 \\
\hline Topsoil reapplication (TS) & 3.77 & 1,16 & 0.070 & 10.63 & 1,69 & 0.005 & 0.08 & 1,69 & 0.779 & 5.76 & 1,13 & 0.030 \\
\hline Wood shavings (WS) & 0.21 & 1,16 & 0.651 & 0.09 & 1,69 & 0.772 & 9.01 & 1,69 & 0.008 & 1.33 & 1,13 & 0.270 \\
\hline Perennial Plant (PP) & 1.32 & 1,16 & 0.267 & 5.85 & 1,69 & 0.028 & 0.01 & 1,69 & 0.913 & 0.14 & 1,13 & 0.811 \\
\hline BSC $\times$ TS & 0.23 & 1,16 & 0.639 & 0.20 & 1,69 & 0.662 & 0.00 & 1,69 & 0.980 & 2.12 & 1,13 & 0.153 \\
\hline BSC $\times W S$ & 0.03 & 1,16 & 0.870 & 0.87 & 1,69 & 0.364 & 0.29 & 1,69 & 0.595 & 1.37 & 1,13 & 0.264 \\
\hline $\mathrm{BSC} \times \mathrm{PP}$ & 2.14 & 1,16 & 0.163 & 0.69 & 1,69 & 0.418 & 1.25 & 1,69 & 0.279 & 0.02 & 1,13 & 0.980 \\
\hline TS $\times W S$ & 1.66 & 1,16 & 0.216 & 1.44 & 1,69 & 0.247 & 1.36 & 1,69 & 0.260 & 2.18 & 1,13 & 0.148 \\
\hline $\mathrm{TS} \times \mathrm{PP}$ & 0.10 & 1,16 & 0.758 & 8.72 & 1,69 & 0.009 & 4.60 & 1,69 & 0.048 & 0.08 & 1,13 & 0.880 \\
\hline WS $\times P P$ & 0.03 & 1,16 & 0.874 & 5.55 & 1,69 & 0.032 & 1.30 & 1,69 & 0.271 & 0.84 & 1,13 & 0.394 \\
\hline $\mathrm{BSC} \times \mathrm{TS} \times \mathrm{WS}$ & 0.00 & 1,16 & 0.982 & 3.82 & 1,69 & 0.068 & 0.67 & 1,69 & 0.424 & 2.04 & 1,13 & 0.159 \\
\hline $\mathrm{BSC} \times \mathrm{TS} \times \mathrm{PP}$ & 0.00 & 1,16 & 0.967 & 0.09 & 1,69 & 0.771 & 3.40 & 1,69 & 0.084 & 0.01 & 1,13 & 0.985 \\
\hline $\mathrm{BSC} \times \mathrm{WS} \times \mathrm{PP}$ & 0.02 & 1,16 & 0.896 & 0.16 & 1,69 & 0.691 & 0.97 & 1,69 & 0.340 & 0.16 & 1,13 & 0.804 \\
\hline$T S \times W S \times P P$ & 0.07 & 1,16 & 0.790 & 1.45 & 1,69 & 0.246 & 0.84 & 1,69 & 0.373 & 0.75 & 1,13 & 0.423 \\
\hline$B S C \times T S \times W S \times P P$ & 0.01 & 1,16 & 0.908 & 1.62 & 1,69 & 0.221 & 0.62 & 1,69 & 0.442 & 1.11 & 1,13 & 0.321 \\
\hline
\end{tabular}


Table S13. Pairwise contrasts between undisturbed plots and experimental field plots for soil chlorophyll $a$ concentration, soil NO3-N and NH4-N concentrations, and soil stability in a biocrust restoration experiment in the eastern Mojave Desert, USA. Experimental field treatments include disturbance (removal of soil surface materials), topsoil reapplication (TS), inoculation with salvaged biological soil crust (BSC), wood shavings (WS), and perennial planting (PP). Topsoil reapplication and perennial planting occurred 14 and 15 months, respectively, after initial construction disturbance, and experimental plots were established 25 months after initial disturbance. All plots were assessed 18 months after experimental plot establishment. Undisturbed plots were included in the overall model to contribute to total variance, but were excluded from consideration in main effects and interactions in model. F statistic and P values represent the comparison between undisturbed plots and experimental field treatments and all their interactions, set as fixed effects. DF is numerator and denominator degrees of freedom. Significant values $\mathrm{P}<0.05$ in bold.

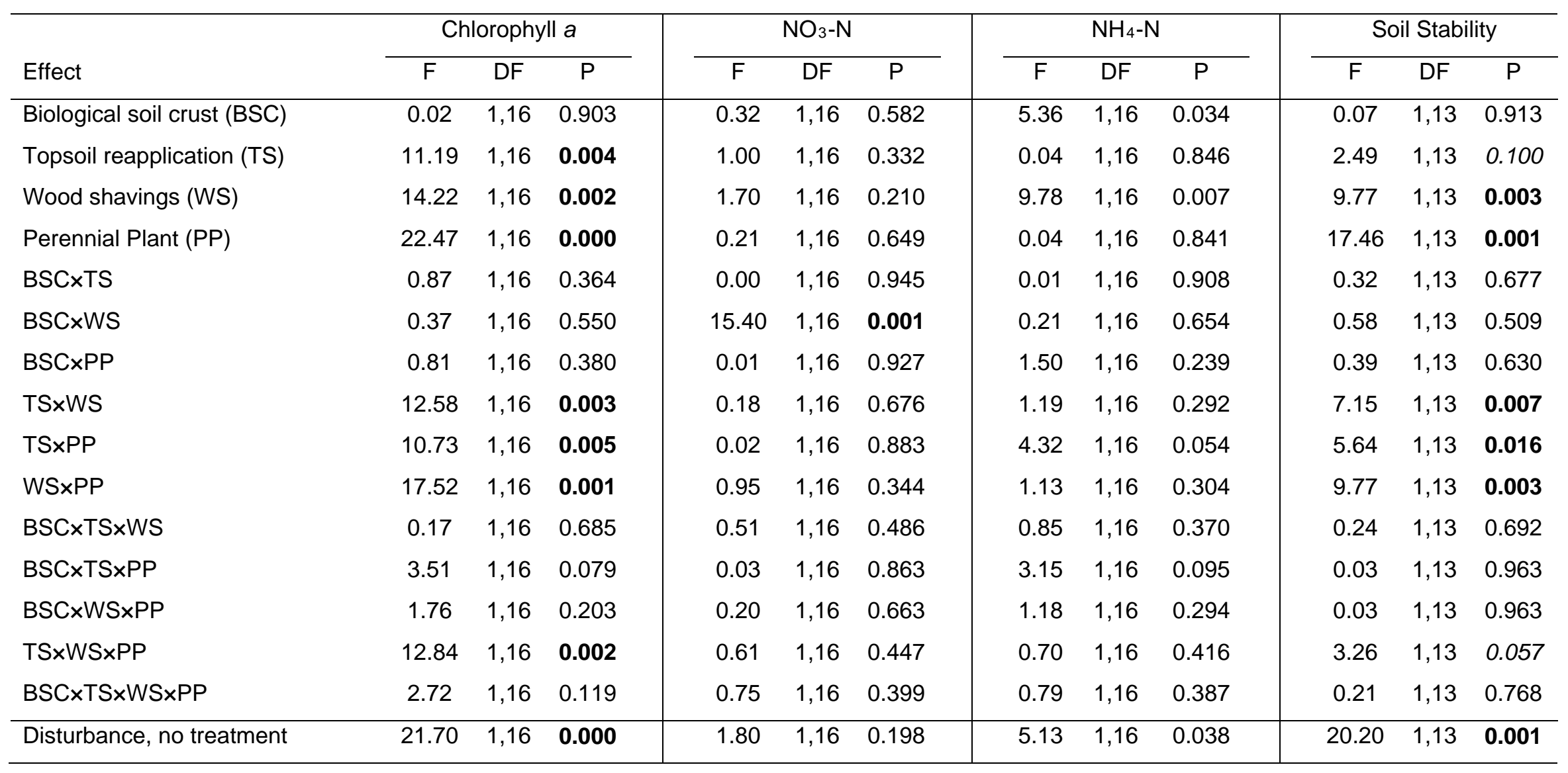


Table S14. Spearman's rank correlation coefficients between response variables from experimental field plots.

Treatments were implemented as a four-factor design applied factorially and included with topsoil reapplication, inoculation with salvaged biological soil crust, wood shavings, and perennial planting in a biocrust restoration experiment in the eastern Mojave Desert, USA. Significant values $\mathrm{P}<0.05$ in bold.

\begin{tabular}{|c|c|c|c|c|c|c|c|c|c|}
\hline Response Variable & $\begin{array}{l}\text { Lichen } \\
\text { Cover }\end{array}$ & $\begin{array}{l}\text { Moss } \\
\text { Cover }\end{array}$ & $\begin{array}{l}\text { Total } \\
\text { Cyanobacteria } \\
\text { Density }\end{array}$ & $\begin{array}{r}\text { By } \\
\text { Filamentous }\end{array}$ & $\begin{array}{l}\text { morpholog } \\
\text { Colonial }\end{array}$ & Unicellular & $\begin{array}{l}\mathrm{NH}_{4-}^{-} \\
\mathrm{N} \\
\mathrm{ppm}\end{array}$ & $\begin{array}{c}\mathrm{NO}_{3}-\mathrm{N} \\
\mathrm{ppm}\end{array}$ & $\begin{array}{c}\text { Chlorophyll } \\
a\end{array}$ \\
\hline Moss Cover & 0.613 & & & & & & & & \\
\hline $\begin{array}{l}\text { Total } \\
\text { Cyanobacteria } \\
\text { Density }\end{array}$ & 0.776 & 0.435 & & & & & & & \\
\hline Filamentous & 0.734 & 0.442 & 0.948 & & & & & & \\
\hline Colonial & 0.690 & 0.478 & 0.831 & 0.731 & & & & & \\
\hline Unicellular & 0.683 & 0.364 & 0.813 & 0.686 & 0.673 & & & & \\
\hline $\mathrm{NH}_{4}-\mathrm{N}$ ppm & 0.377 & 0.209 & 0.339 & 0.297 & 0.275 & 0.358 & & & \\
\hline $\mathrm{NO}_{3}-\mathrm{N}$ ppm & 0.170 & 0.162 & 0.090 & 0.085 & 0.045 & 0.039 & 0.243 & & \\
\hline Chlorophyll a & 0.837 & 0.450 & 0.753 & 0.728 & 0.717 & 0.638 & 0.349 & 0.069 & \\
\hline Soil Stability & 0.789 & 0.537 & 0.762 & 0.751 & 0.675 & 0.580 & 0.277 & 0.067 & 0.775 \\
\hline
\end{tabular}


Literature Cited

Alwathnani, H. and J. R. Johansen. 2011. Cyanobacteria in soils from a Mojave Desert ecosystem. Monographs of the Western North American Naturalist 5:71-89.

Boyer, S. L., J. R. Johansen, V. R. Flechtner, and G. L. Howard. 2002. Phylogeny and genetic variance in terrestrial microcoleus (Cyanophyceae) species based on sequence analysis of the 16S rRna gene and associated 16S-23S ITS region1. Journal of Phycology 38:1222-1235. 